This PDF is a selection from a published volume from the National Bureau of Economic Research

Volume Title: NBER Macroeconomics Annual 2008, Volume 23

Volume Author/Editor: Daron Acemoglu, Kenneth Rogoff and Michael Woodford, editors

Volume Publisher: University of Chicago Press

Volume ISBN: 0-226-00204-7

Volume URL: http://www.nber.org/books/acem08-1

Conference Date: April 4-5, 2008

Publication Date: April 2009

Chapter Title: The Timing of Labor Market Expansions: New Facts and a New Hypothesis

Chapter Author: Giuseppe Moscarini, Fabien Postel-Vinay

Chapter URL: http://www.nber.org/chapters/c7270

Chapter pages in book: (p. 1 - 52) 


\title{
The Timing of Labor Market Expansions: New Facts and a New Hypothesis
}

\author{
Giuseppe Moscarini, Yale University and NBER
}

Fabien Postel-Vinay, University of Bristol and Université de Paris I (Panthéon-Sorbonne)

\section{Introduction}

The cyclical behavior of (un)employment and wages still poses a formidable challenge to macroeconomists. No other aspect of the business cycle has been as widely studied and remains as poorly understood. While a consensus has slowly emerged on the importance of search frictions to explain equilibrium unemployment, as well as residual wage inequality unexplained by observable worker and firm characteristics, we still do not know how wages are set in practice. When labor demand rises, driven by higher productivity or real demand for goods, how is it exactly that workers obtain higher wages? And why do wages rise gradually and slowly over business cycle expansions?

The search-and-matching business cycle literature commonly assumes that wages are settled through a bargaining process but does not identify the source of parties' bargaining power. The search literature on wage inequality, invariably cast in steady state and abstracting from aggregate fluctuations, typically assumes that firms have full monopsony power and make take-it-or-leave-it offers of employment contracts. To reconcile this intuitive and plausible assumption with the reality of worker rents and wage inequality and to avoid the Diamond (1971) paradox, Burdett and Mortensen (1998) identify the source of workers' bargaining power in a form of moral hazard. Specifically, workers obtain more than their reservation wage in order to be induced to quit their previous employer and, once hired, to decline future outside offers. Poaching is the engine of wage growth and differentiation for individual workers.

In this article we argue that the same poaching mechanism also transmits aggregate productivity shocks to wages and employment. Firms offer higher wages only when they run out of cheap unemployed job 
applicants and find it profitable to steal employees from their competitors, who in turn fight back and start paying more to retain their workers. Our argument builds on a set of new facts about aggregate dynamics in U.S. labor markets over the last two decades that we document by drawing in part from newly available data sets. These facts suggest a new view of how business cycles evolve and mature. We investigate whether this view is consistent with the transitional dynamics of the Burdett-Mortensen equilibrium search model. In Moscarini and Postel-Vinay (2008), we develop the first theoretical analysis of the outof-steady-state behavior of the Burdett-Mortensen model. ${ }^{1}$ In the present paper, we build on those results and present a quantitative simulation exercise to gauge the extent to which the Burdett-Mortensen model's quantitative predictions are congruent with the facts that we uncover.

The three new facts concern three seemingly unrelated time series. First, the share of employment at small firms and establishments declines through the 1990s and 2000s expansions and crosses below its overall average around the middle of each decade; in contrast, large firms are hit particularly hard by recessions and then slowly recover employment share. Alternatively, the difference between the growth rate of employment at large firms/establishments vis-à-vis small ones is strongly procyclical, its troughs and peaks roughly coinciding with NBER business cycle dates and rising uniformly in between. Second, the monthly employer-to-employer (EE) worker transition rate declines through the first half of each decade and rebounds starting in 1996 and in 2004. Large employers poach more than small ones late in the 1990s, not so after the ensuing recession. Third, various measures of detrended worker compensation exhibit a behavior quite similar to the EE rate, both economywide and for each employer size class, with workers at larger employers earning more at all points in time. All in all, simultaneously and at the midpoint of the expansion, several years after the previous trough, the unemployment rate crosses below trend, large employers take over net job creation, workers start quitting more from job to job, and wages accelerate.

These facts suggest the following view of aggregate expansions. Following a positive aggregate shock to labor demand, wages respond little on impact and start rising when firms run out of cheap unemployed hires and start competing to poach and to retain employed workers. Early in an expansion, the large pool of unemployed workers sustains firms' monopsony power. Wages remain low, firms hire mostly from unemployment, and relatively few workers quit from job to job. As the reservoir of unemployment dries out, more productive firms find 
it profitable to start raising wages to raid workers from less productive competitors. They respond by paying their workers more to retain them. Wages rise both within firms and as workers upgrade by quitting to higher-paying employers. Workers quit mostly from small, lowpaying firms to large, high-paying firms. The growth in the employment of large firms is fueled by the stock of employment at small firms, which takes some time to replenish after a recession. Hence, employment at small firms grows faster and peaks earlier than at large firms. As employment at small firms peaks and poaching becomes a more important source of hiring, the EE rate picks up.

The facts that we highlight and use to support the above view of labor market expansions are limited in time and scope by data availability. The bulk of our data cover only the last two expansions, which have been uniquely "jobless." Thus we do not claim to have identified new business cycle stylized facts. What we do claim is that the patterns we point out for the last two expansions shed some light on the workings of labor markets in general, mainly by identifying the hiring behavior of large firms as an important channel for the propagation of aggregate shocks.

We formalize those views within a wage-posting model à la Burdett and Mortensen. A calibrated example of the transitional dynamics of the wage-posting model, following an aggregate productivity shock, exhibits many of the qualitative features of our new facts. Larger firms pay more at any point in time. Employment growth is faster at small firms early on, and then large firms take over as they poach employees. Wages rise slowly at first and then accelerate. The job-to-job quit rate rises for some time as the pool of workers at small firms, vulnerable to poaching, expands.

A detailed theoretical analysis of the transitional dynamics of the Burdett-Mortensen model, which we simulate in this paper, is available in Moscarini and Postel-Vinay (2008). Because of the known complexity of this problem, in the present paper we restrict attention to a certain class of equilibria (which we call rank-preserving), as defined and motivated in the text. We further confine the analysis to the deterministic transition to a steady state following an unanticipated, permanent aggregate productivity shock. Before the shock, firms pay constant wages in a stationary world. After the shock, firms post and commit to new contracts that pay wages contingent only on either calendar time or the unemployment rate. All workers in a firm are paid the same wage, no matter when hired or from where. Workers receive offers both off and on the job and decide which ones to accept on the basis of their 
implied present discounted value of wages, taking future transitions into account.

In our computed example, firms back-load wages to the late part of the expansion. In steady-state analysis of wage-tenure contracts, wages are back-loaded late in the employment relationship to piggyback on future poachers. If workers are risk neutral, back-loading is extreme in the form of a step function of tenure (Stevens 2004). Gradual wage growth requires risk aversion and extreme market incompleteness as a motive for consumption smoothing (Burdett and Coles 2003). In our setup, wages grow slowly even if workers are risk neutral and capital markets are perfect; wage back-loading occurs over calendar time, not over tenure. Beyond the piggybacking motive, the increasing scarcity of cheap hires from unemployment makes raising wages more attractive in order to poach employed workers, thus also to retain own employees.

While the process of upgrading from job to job is usually described as climbing a wage ladder, our non-steady-state analysis reveals that it is best described as jumping from a "wage escalator" up to a higher one. All workers benefit as wages rise within firms. In addition, job changers rise from one rising wage profile to a higher one at another firm. Therefore, aggregate wages rise for two reasons: on the intensive margin, all workers are paid progressively more, and on the extensive margin, workers move to higher-paying firms.

In our example, job changers exhibit faster (so, in this limited sense, more procyclical) wage growth than job stayers. This prediction is consistent with the main findings of the literature on real wage cyclicality (Bils 1985; Beaudry and DiNardo 1991; Solon, Barsky, and Parker 1994). This literature, however, has been hampered by the lack of high-frequency, reliable information on job-to-job transitions in a representative sample. We present such evidence from the monthly Current Population Survey (CPS) starting in 1994, when it first became available, but we have not yet linked it to individual wage information. A similar view holds that workers flow from low-wage to high-wage industries in an expansion, a "cyclical upgrading of labor" (Okun 1973). This is based on the observation that high-wage industries have more cyclical employment. Barlevy (2001), however, shows that the interindustry wage gains reflect to some extent the compensating differential associated with accepting riskier jobs. While the source of interindustry wage differentials is still an open question, we show that the patterns of employment growth by firm and establishment size that we uncover hold within, and not across, industries. 
Our example also features a strong propagation in wages and labor productivity, which keep rising years after the initial shocks, although the unemployment rate transition's half-life is just a few months. The main reason is that job-to-job transitions in the data are an order of magnitude slower than the reallocation from unemployment to employment. Thus, the upgrading process is slow, and so is the rise in labor productivity after an initial jump following the shock. The propagation is less pronounced for the EE rate. We are, however, ignoring further sources of propagation of the unemployment rate, such as endogenous labor force participation. This is likely to rise in the expansion, feeding the market with relatively cheap candidates for hiring from unemployment and delaying the moment when large firms have to start raising wages aggressively to poach workers, the small firms have to respond to retain them, and the EE rate peaks.

Section II lays out the facts and offers an intuitive explanation of them based on the Burdett-Mortensen equilibrium search model. The rest of the paper discusses the theoretical model and its quantitative predictions. Section III describes the basic economic environment. Section IV characterizes the dynamic labor market equilibrium and explains our solution strategy. Details and results of a simple calibration exercise are presented and discussed in Section V. Finally, Section VI presents conclusions and gives some thoughts about possible further research avenues.

\section{Aggregate Labor Market Fluctuations: New Evidence}

\section{A. Definitions and Overview}

In order to organize the new evidence under a common heading, we open this section by providing our own definition of a tight labor market. We apply an HP (Hodrick-Prescott) filter to both the monthly civilian unemployment rate and the monthly civilian employment to working-age population ratio (E/POP ratio) from the Bureau of Labor Statistics (BLS) in 1948:1-2008:1. We choose a smoothing parameter equal to $10^{5} \times 3^{2.25}$, which corresponds to Shimer's (2005) choice of $10^{5}$ at a quarterly frequency. ${ }^{2}$ In figure 1 we plot the deviations of the unemployment rate and the E/POP ratio from their respective postwar trends. ${ }^{3}$ We show the resulting detrended series by zooming only on 1975-2008, because this is the longest span covered by our other data series. Clearly, the unemployment rate crosses its trend from above in 1977, 1984-85, 1995-96, and 2005. In the second and third episodes, it 


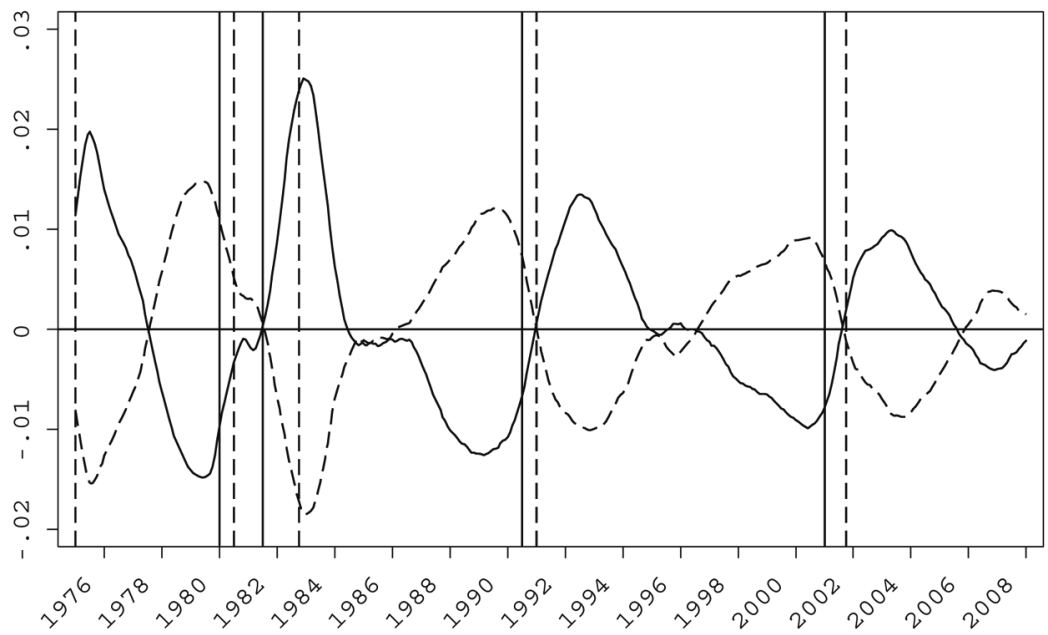

Fig. 1. Employment and unemployment rates. The solid line is the unemployment rate. The dashed line is the E/POP ratio. HP-filtered U.S. monthly data, 1978:1-2008:1. HP trends are calculated over the entire postwar series (1948:1-2008:1) with smoothing parameter $10^{5} \times 3^{2.25}$, then MA smoothed. The solid (dashed) vertical line indicates NBER peaks (troughs). Source: BLS and authors' calculations.

hovers around trend for almost 2 years but is higher before and lower after that point in time during an expansion, further corroborating our detrending choice.

Armed with this graph, we define the labor market to be tight when the unemployment rate first falls below its trend and remains there for at least a year thereafter. The window of at least 12 months of consecutive observations above or below trend, before/after first crossing it, is necessary to eliminate neutral phases, when the unemployment rate hovers near trend. Notice that this definition does not coincide with that of an expansion or recession according to NBER dates (materialized on all figures by vertical lines, solid for peaks and dashed for troughs). Indeed, the phases of labor market neutrality occur typically roughly midway between troughs and peaks, although the unemployment rate itself does not have symmetric dynamics, typically rising faster than it declines. From every cyclical trough in the sample period, the labor market starts slack, then shifts into neutral, and finally tightens, until the next peak.

Although we have chosen to couch this definition in terms of the unemployment rate, it is evident from figure 1 that the E/POP ratio is an equally good indicator of labor market tightness as defined above, since 
the cyclical behavior of the $\mathrm{E} / \mathrm{POP}$ ratio is essentially the mirror image of that of the unemployment rate (the correlation coefficient of the two series over the entire postwar period is -0.92). In other words, as far as labor market cycle dating is concerned, cyclical variations in labor force participation can be ignored to a first approximation. We will implicitly make this approximation throughout the paper, especially in the theory in which the participation margin will be shut down altogether.

The three new facts that we uncover and document in this section concern three seemingly unrelated time series in the last few decades. Armed with our definition of tight and slack labor markets, we can briefly characterize them as follows. We first describe them verbally and later graphically rather than reporting correlations of detrended series, because many of the available time series cover only a couple of business cycles.

Fact 1. Small firms and establishments grow in size faster than large ones when the labor market is slack, and vice versa when the labor market turns tight. Therefore, the firm/establishment size distribution gets compressed in a slack labor market and becomes more unequal in a tight one.

Fact 2. The rate at which employed workers quit to other jobs is above trend in a tight labor market and below trend in a slack labor market.

Fact 3. The annual growth rate of real wages or weekly earnings is above its trend in a tight labor market and below in a slack labor market.

We now describe the three facts in detail.

\section{B. The Cyclical Dynamics of the Firm/Establishment Size Distribution}

Most of the new empirical evidence that we present in this paper pertains to fact 1 , the relative timing of net job creation within a business cycle by size classes. Essentially, of the total job creation observed from cyclical trough to peak, more of it occurs early on in the expansion for small firms/establishments than for larger ones. In recessions, large firms/establishments are hit particularly hard. Notice that this fact does not say that most job creation occurs at small establishments, a wellknown subject of political rhetoric and confusion. Our finding is about the movement of the relative growth rate. While the political debate is typically focused on growth rates, it is still the case that the number of jobs added by large establishments is higher than that added by small ones or by entrants at nearly all points in the aggregate expansion. ${ }^{4}$

Reflecting the dual structure of its statistical agencies, the U.S. federal government has produced two comprehensive and independent 
sources of information on firms and establishments, specifically on their count, employment, payroll, industry, and location. Business Employment Dynamics (BED) is a data set providing quarterly information on job flows and firm sizes since 1992. It is based on the quarterly Census of Employment and Wages, which in turn collects information from the state and federal Unemployment Insurance (UI) systems accruing to the BLS for this purpose. The BED covers all employers subject to UI taxes, which account for $98 \%$ of employment. While used primarily to measure job flows, information on employment stocks is publicly available when aggregated into nine classes of firm size. ${ }^{5}$

The second data set is the County Business Patterns (CBP), which is maintained at the Bureau of the Census and derives from the Business Register and quinquennial economic censuses. The publicly available information from the CBP that we have been able to secure consists of annual information on counts, employment, industry, payroll, and location for all U.S. firms (since 1988) and establishments (since 1990), as well on nonemployers (self-employed) for 1992 and 1997-2005. Limited longitudinal information on employment growth by initial firm size in CBP is publicly available, under the name of Business Information Tracking Series (BITS) at the Census Bureau and Dynamic Size Information at the Small Business Administration. ${ }^{6}$

\section{Employment Shares and Growth Rates by Size Classes}

The firm size distribution series from BED, available in 1992-2007, show that small (in terms of employment) firms had a countercyclical share of total employment. They concentrated most of their job creation in the early part of the 1990s expansion and promptly expanded their employment after 2001. Conversely, large firms concentrated most of their 1990s job creation after 1996 and again failed to create jobs in the first part of the 2000s expansion. This pattern is observed across nine firm size classes and is exemplified in figure 2, which plots employment shares for four different classes. The recoveries of the early 1990s and 2000s were "jobless" mainly at large firms, whereas the strong job creation of the late 1990s, in the mature phase of the expansion, was concentrated mainly in large firms. ${ }^{7}$

The evidence for firms from BED can also be illustrated in terms of growth rates of employment rather than employment shares. The top two panels of figure 3 plot average employment growth rates of large and small firms. The bottom two panels report the difference in average employment growth rates between large and small firms (the two series 

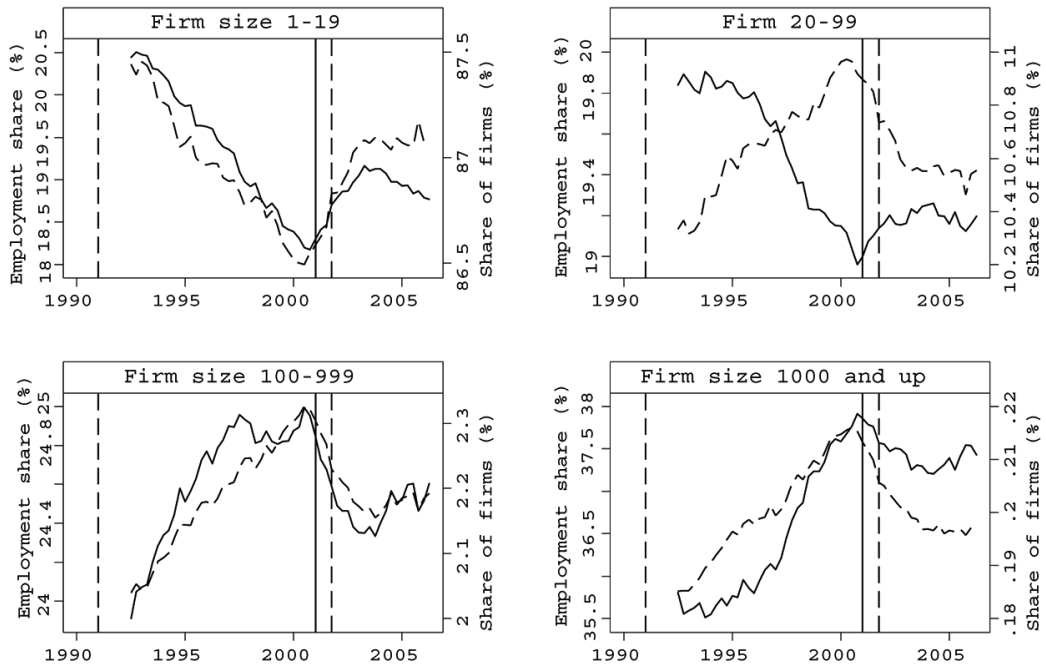

Fig. 2. Fraction of firms and employment shares-small vs. large firms. The solid line is the unemployment rate. The dashed line is the share of firms. The solid (dashed) vertical line indicates NBER peaks (troughs). Source: BED (quarterly) and authors' calculations.
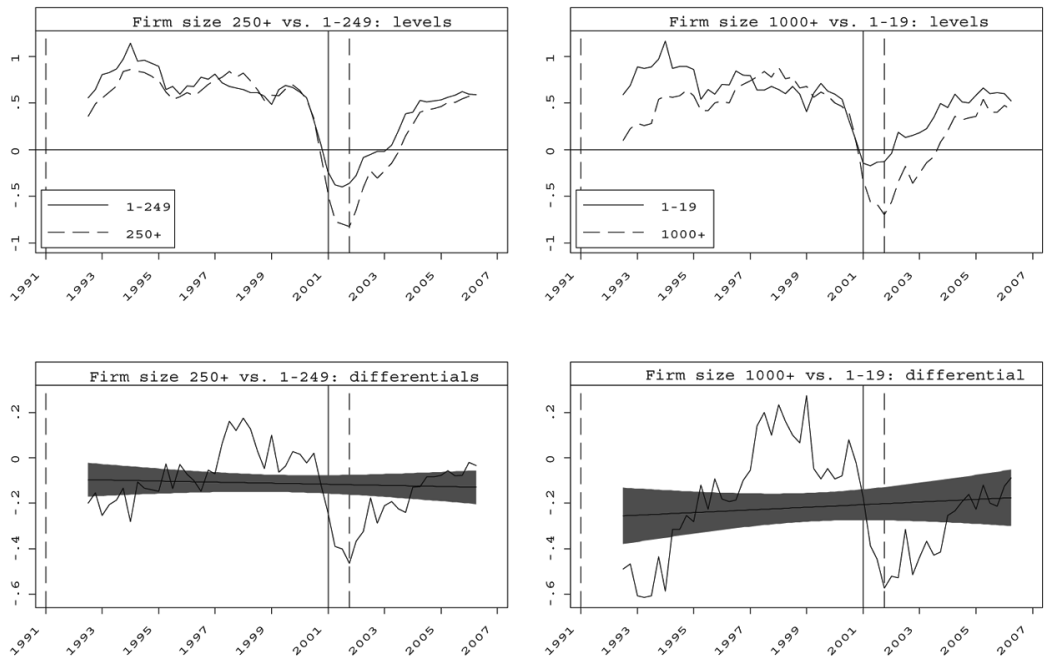

Fig. 3. Difference in average growth rates of employment across firm size classes. Differential firm size growth, MA smoothed. The solid (dashed) vertical line indicates NBER peaks (troughs). Source: BED and authors' calculations. 
on the corresponding top panel): when the series is positive, large firms grow faster, and vice versa. ${ }^{8}$ The two columns of figure 3 relate to two different definitions of the "small" and "large" classes, as indicated on each panel. This highlights more vividly the pattern of figure 2: wherever one places the cutoff between small and large firms, small firms appear to have grown (relatively) faster than large firms at the beginning of the 1990s expansion and slower later on in that same expansion. A similar pattern seems to appear again at the beginning of the 2000s expansion. Focusing on the top two panels of figure 3, one can further decompose that pattern by noticing that average size growth of small firms actually trends down over the expansion, whereas that of large firms does not trend. This is why large firms take over on average. Hence these series of average growth rates by firm size class, albeit all clearly procyclical, diverge to some extent.

To further illustrate this pattern, figure 4 shows the comovements between growth differentials across firm size classes (the series on the right panel of fig. 3) and the aggregate unemployment rate. ${ }^{9}$ Although the two series fluctuate with a different amplitude, one sees that they exhibit very strong comovements: the correlation between growth rate differentials and the unemployment rate series is about -0.76 over the observation window. ${ }^{10}$

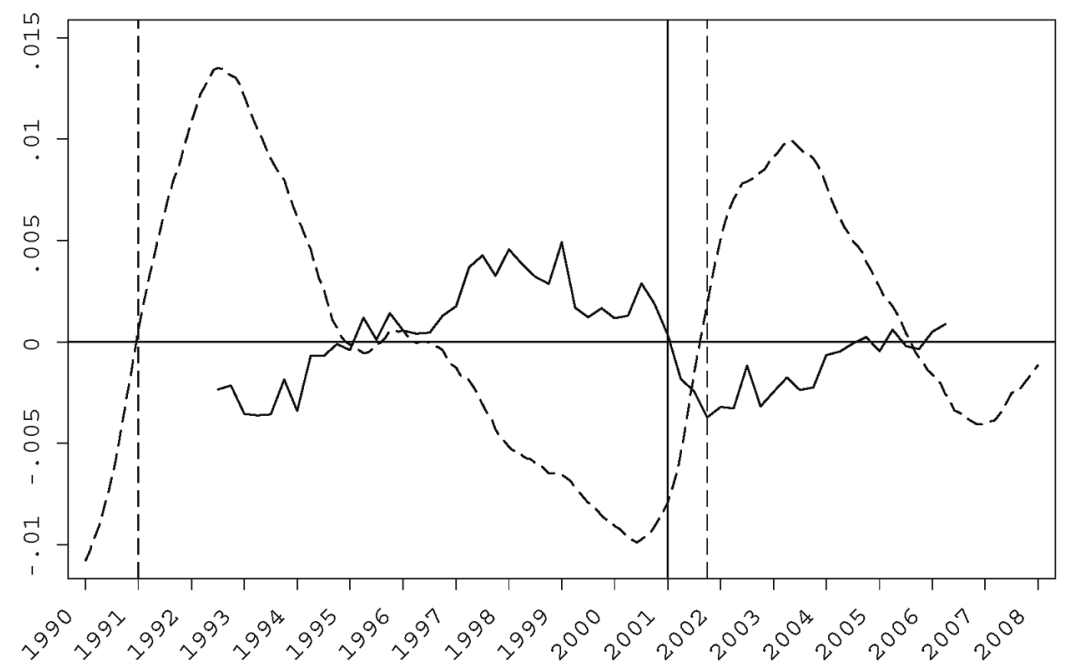

Fig. 4. Growth rate differentials, employment, and unemployment rates. The solid line is differential firm size growth, and the dashed line is the unemployment rate. All series are MA smoothed. The solid (dashed) vertical line indicates NBER peaks (troughs). Source: BED, BLS, and authors' calculations. 
Similar firm-level evidence can be constructed at an annual frequency, but beginning in 1988, from the CBP data, which are available at the firm (as well as establishment) level. CBP conveys only information on employment shares, which is our main focus, and not on firm counts, since this particular version of the data aggregates nonemployers with small firms in some years and not in others. This inconsistency makes cross-date comparisons of firm counts impossible but does not affect employment since we have been excluding the self-employed throughout. Figure 5 repeats figures 2 and 3 using CBP firm-level data and confirms the pattern already observed in BED, not only for the 1990s and early 2000s but also around the previous recession, since we now also encompass 1988-91.

While the distinction between firms and establishments is often a thorny issue in theoretical exercises, fortunately for us this will not be the case. The same empirical phenomenon emerges from establishmentlevel data using the CBP since 1990 (see fig. 6, which replicates fig. 2 for establishments). The pattern of establishment size dynamics over the last two business cycles closely resembles that of firm size dynamics, partly owing to the fact that most (small) firms are mono-establishment. More generally, however, large establishments tend to be part of large
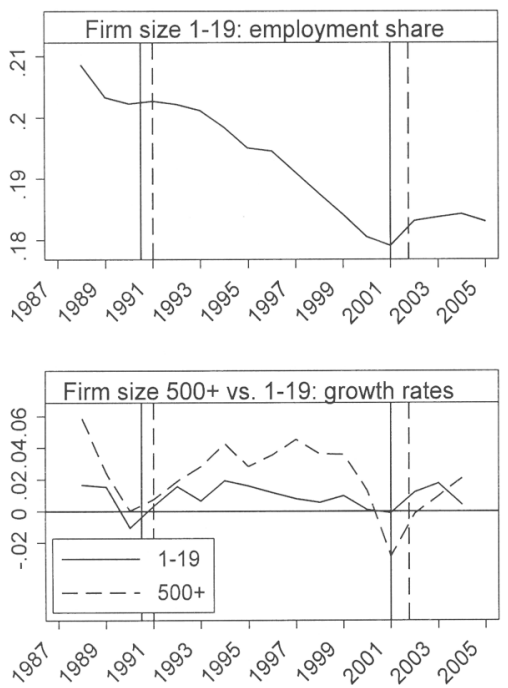
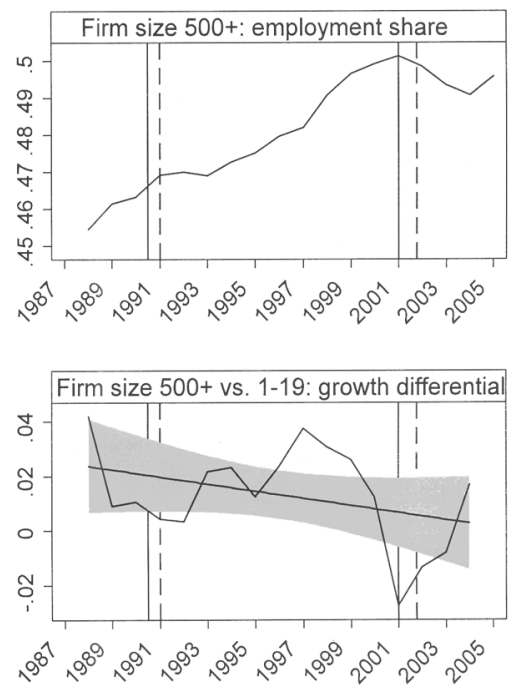

Fig. 5. Employment shares and employment growth by firm size classes, CBP firm-level data. Employment shares (top row) and growth rates (bottom row). The solid (dashed) vertical line indicates NBER peaks (troughs). Source: CBP (firm-level data set) and authors' calculations. 

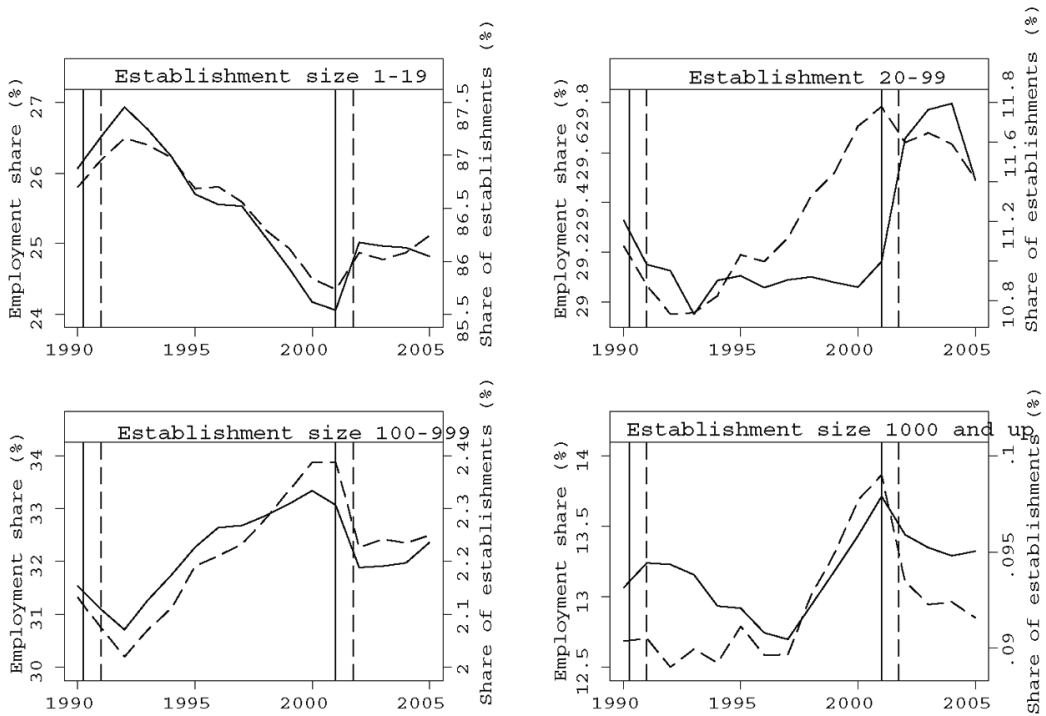

Fig. 6. Employment shares by establishment size. The solid (dashed) vertical line indicates NBER peaks (troughs). Source: CBP (yearly) and authors' calculations.

firms. If one looks across firm size bins in the CBP, the correlation between the average number of establishments of the firm and the average size of employment per establishment is close to one.

Overall, we conclude that large firms and establishments grow relatively faster when the labor market is tight according to our earlier definition, and vice versa for small ones.

\section{The Reclassification Bias}

While our last statement might appear plausible and intuitive, the following issue still needs to be resolved: the identity of firms in different size classes changes over time. Firms and establishments are reclassified at each observation date according to their new size. Indeed the BED data set explicitly applies "dynamic allocation" of firms to size classes; that is, it even changes class assignments at an infraquarterly frequency for firms crossing the line between two size classes. Thus, in a growing economy, where firms gain size on average, one would expect the distribution of firm size to rise in a stochastic dominance sense. We refer to this issue as the reclassification bias.

To eliminate reclassification, we need longitudinal links on firms/ establishments to fix their assignment to size classes (or average wage 
classes, or value-added classes) at a cyclical trough then track over the expansion the shares of employment at these classes of employers, without reclassifying them every period. This would allow us to verify, for example, whether firms/establishments that are initially small often leapfrog and overtake the initially larger ones, a phenomenon that would invalidate our interpretation of the facts.

To this purpose, we utilize two publicly available longitudinal data sets on U.S. firms. The first is Compustat, which comprises only listed companies. We fix firm identities in 1975 and classify them once and for all in size bins (by employment): large above 5,000 employees and small fewer than 5,000. The reason for the large size cutoff is that listed companies are very large. Then, for each year from 1976 to 2005, we calculate the growth rate of employment over the past year at (initially) large firms and subtract the growth rate of the other initially small firms in the sample. We plot this difference in growth rates in figure 7 in a way that mimics figure 3 . Consistent with the pattern uncovered in the BED, over three full business cycles this difference in growth rates is procyclical and crosses zero when the labor market turns tight.

Compustat is not a representative sample, but the CBP is. Although the underlying source of micro data is not publicly available, the Census Bureau publishes employment growth by firm size, where firms are

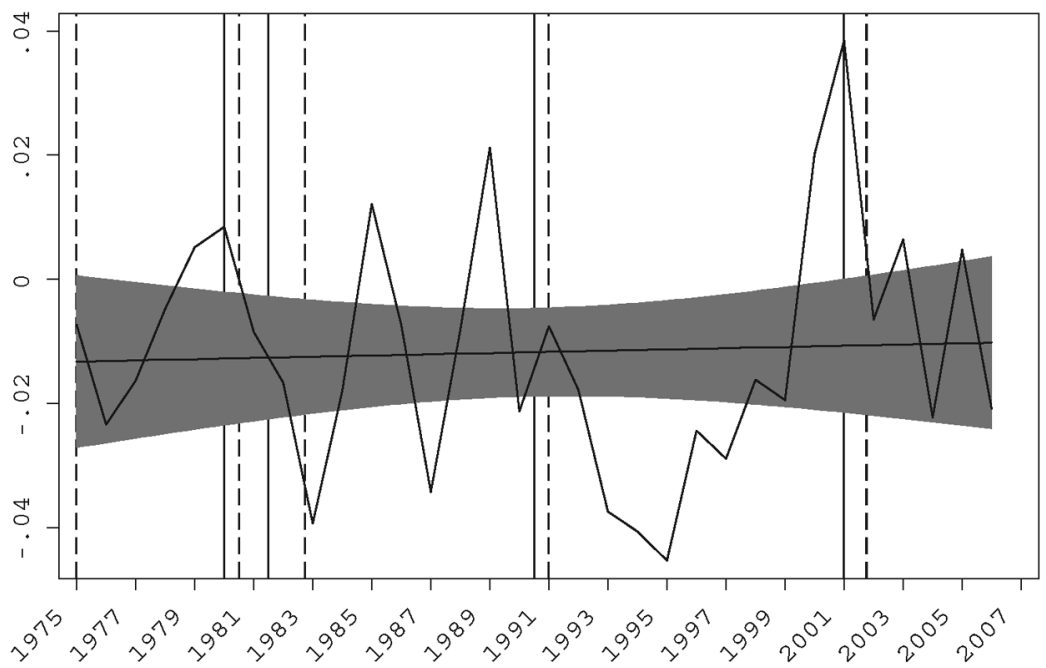

Fig. 7. Growth rate differentials across size classes for a fixed sample of publicly traded U.S. companies classified by size in 1975. Differential firm size growth: over 5,000 minus under 5,000 employees. The solid (dashed) vertical line indicates NBER peaks (troughs). Source: Compustat North American files and authors' calculations. 
assigned to categories according to size on March 12 each year and stay in the same class for 1 year. ${ }^{11}$ This data set, BITS, exploits the longitudinal links in CBP for just one year at a time. In figure 8 we plot our findings from BITS, again in terms of differences in growth rates. Every year since 1989, that is, since BITS data are publicly available, we compute the growth rate of employment over the subsequent year among firms that started above 500 employees in March of year $t$ and subtract the growth rate for the 1-499 employees size class. A positive number indicates that firms that were larger in March of year $t$ grew faster than the other ones until March of year $t+1$, when they were reclassified after the relevant growth rates were computed. The evidence is again fairly clear-cut, whether one detrends or not: small firms grow faster early in an expansion; the pattern then slowly reverses, to switch back abruptly during recessions. The differences in annual size growth rates are large.

\section{Industry-Level Evidence}

An additional appeal of the CBP / BITS data set is that it provides industrylevel information. This enables us to gauge whether the pattern identified in this subsection is also observed within industries or whether it mostly reflects a reallocation of labor across industries. More specifically, is it the

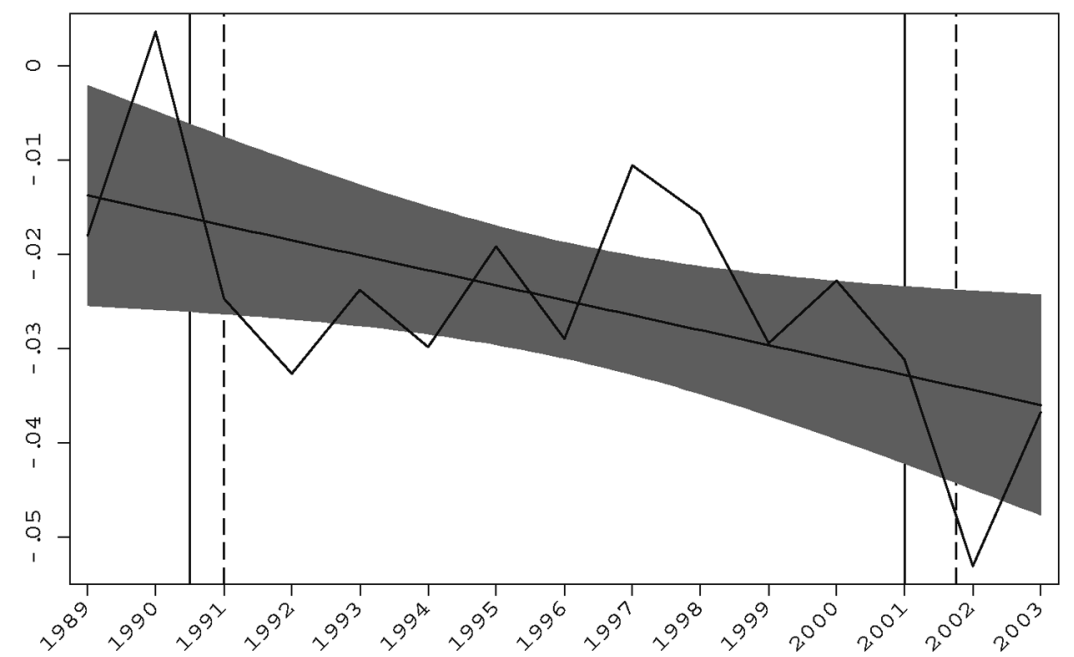

Fig. 8. Growth rate differentials across size classes for all U.S. firms, reclassified every year in March after computing the growth rate over the past year. Differential firm size growth: over 500 minus under 500 employees. The solid (dashed) vertical line indicates NBER peaks (troughs). Source: BITS and authors' calculations. 
case that small firms exhibit faster growth at early stages of an expansion whereas large firms take over later on uniformly across industries, or is it that job creation early on is concentrated at industries that tend to be populated by smaller firms, whereas industries with larger firms have a "slower start"? The answer turns out to be the former.

Figure 9 plots series equivalent to the one displayed in figure 8 for eight broad industries. ${ }^{12}$ Although industry-level data are inevitably more noisy, the aggregate pattern shown on the upper-left panel (a repetition of fig. 8) seems by and large to apply across industries. In all cases, without exceptions, the disaggregated industry series drop on or around recessions. Those series cross the trend from below only around 1996 in five of the eight industries: construction; transportation, communication, and public utilities (TCPU); wholesale trade; finance, insurance, and real estate (FIRE); and services. The pattern is similar in manufacturing, except for the sharp drop in 1996. Manufacturing is the industry in which the firm/employment size distribution is most skewed toward large values, an outlier in the economy at large, so small firms play a lesser role. In fact, the largest size cutoff available in BITS is 500 employees, which is well above the median firm size for all industries but is well below the median for manufacturing; so this data set is not really informative for manufacturing, where the vast
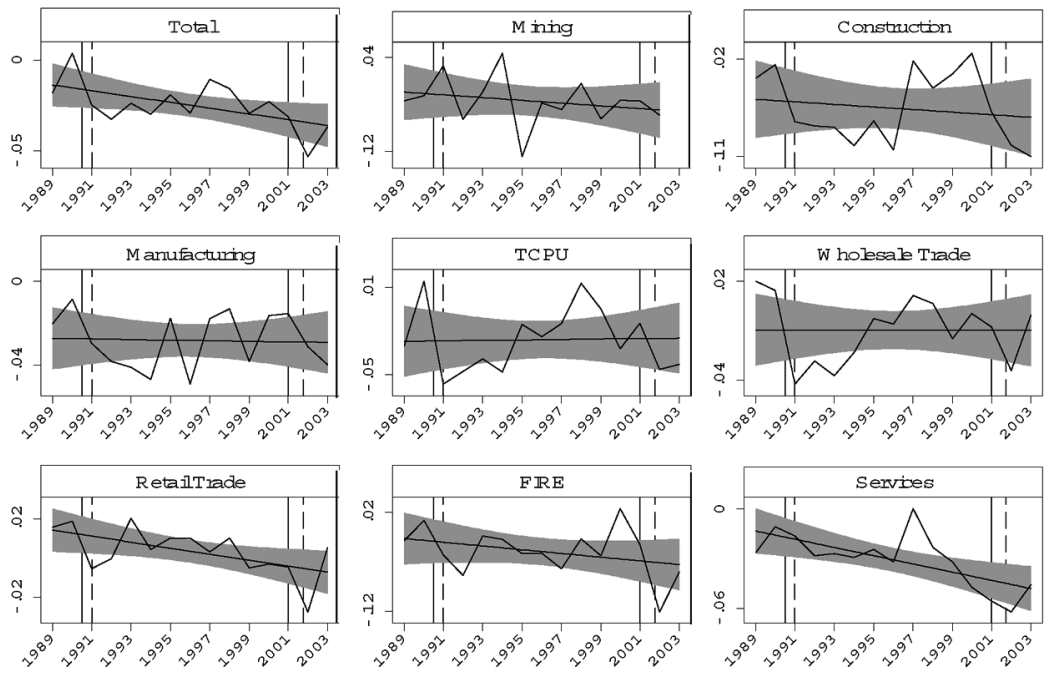

Fig. 9. Growth rate differentials across size classes for all U.S. firms, size classes fixed over a year, by industry. Differential firm size growth: over 500 minus under 500 employees. The solid (dashed) vertical line indicates NBER peaks (troughs). Source: BITS and authors' calculations. 
majority of firms need to be classified as "large."13 The pattern is less clean in retail trade, but even there small firms grow faster early on after the recessions. Mining is the only (small) industry that does not fit the general picture at all. The effect on the other (between-industry) margin can also be assessed using the BITS data, for instance, by looking at the difference in employment growth between industries populated by firms whose size is above the economywide average and industries with comparatively smaller firms. A plot of this difference (not reported here) suggests that this between-industry difference has no particular cyclical pattern, contrary to the within-industry series plotted in figure 9. This finding will make an interesting contribution to our discussion of how to interpret the facts below.

\section{The Cyclical Dynamics of Employer-to-Employer Transitions}

Monthly CPS data available since 1994 allow the construction of monthly EE transition rate series. ${ }^{14}$ Such a series, compiled by Moscarini and Thomsson (2007), is plotted in figure 10 (in deviation from HP trend), together with the unemployment rate series from figure 1 to highlight the EE rate's cyclical behavior in terms of our adopted definition of labor market tightness.

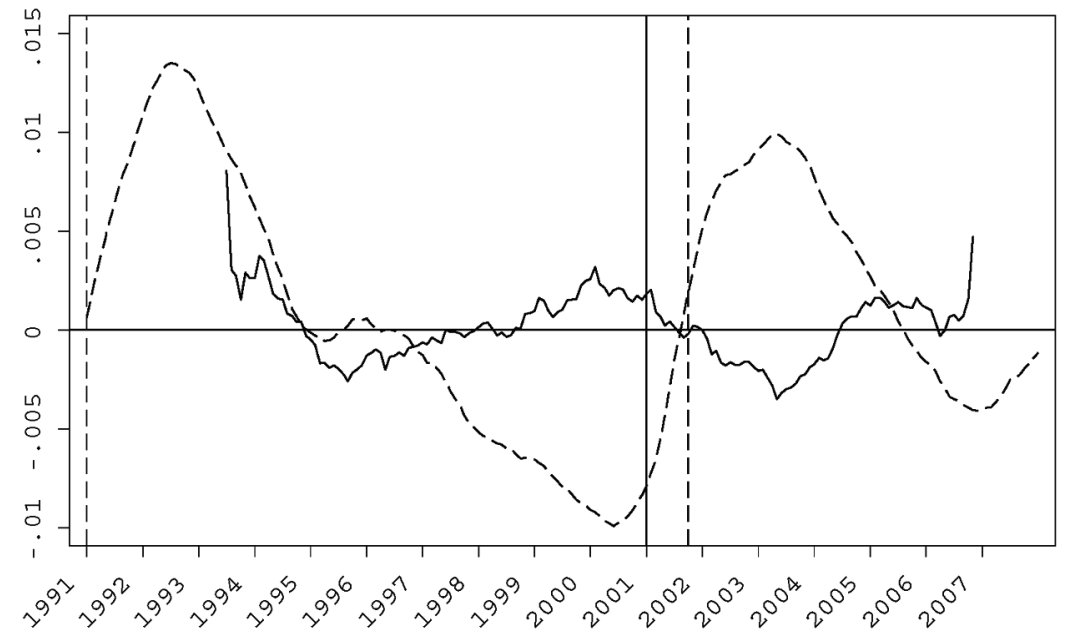

Fig. 10. Monthly transition rate of employed workers to other employers. The solid line is the EE rate, and the dashed line is the unemployment rate. EE rate: U.S. monthly data, deviation from linear trend, MA smoothed. The solid (dashed) vertical line indicates NBER peaks (troughs). Source: CPS, BLS, Moscarini and Thomsson (2007), and authors' calculations. 
Our guiding hypothesis relates the time and cross-employer variation in poaching activity to wage growth. Publicly available data from the Census's Survey of Income and Program Participation (SIPP) ${ }^{15}$ conveys information about the workforce size of an individual's current employer (employing establishment) as well as individual job histories. This allows a crude analysis of the poaching activity of establishments as a function of their size. Figure 11 plots a measure of the fraction of new hires coming from another employer (i.e., following an EE transition) for three categories of hiring establishment size. ${ }^{16}$ In other words, it plots a measure of the importance of poaching in the recruitment activity of establishments, by size of the hiring establishment. Changes in the design of the SIPP and other data limitations restrict the period over which that indicator can be constructed to the years shown on figure 11. While this admittedly constitutes very limited evidence, we still notice the following two points. First, and consistent with the evidence presented in figure 10, poaching was more intense in the latter half of the 1990s expansion than in the immediate aftermath of the 2001 recession. This is true for all three categories of establishment size. Second, larger establishments almost always poach more than smaller ones. This difference in "poaching intensity," however, is more pronounced in 1997-99, when the labor market turns tight, than in 2002-4, when it is slack.

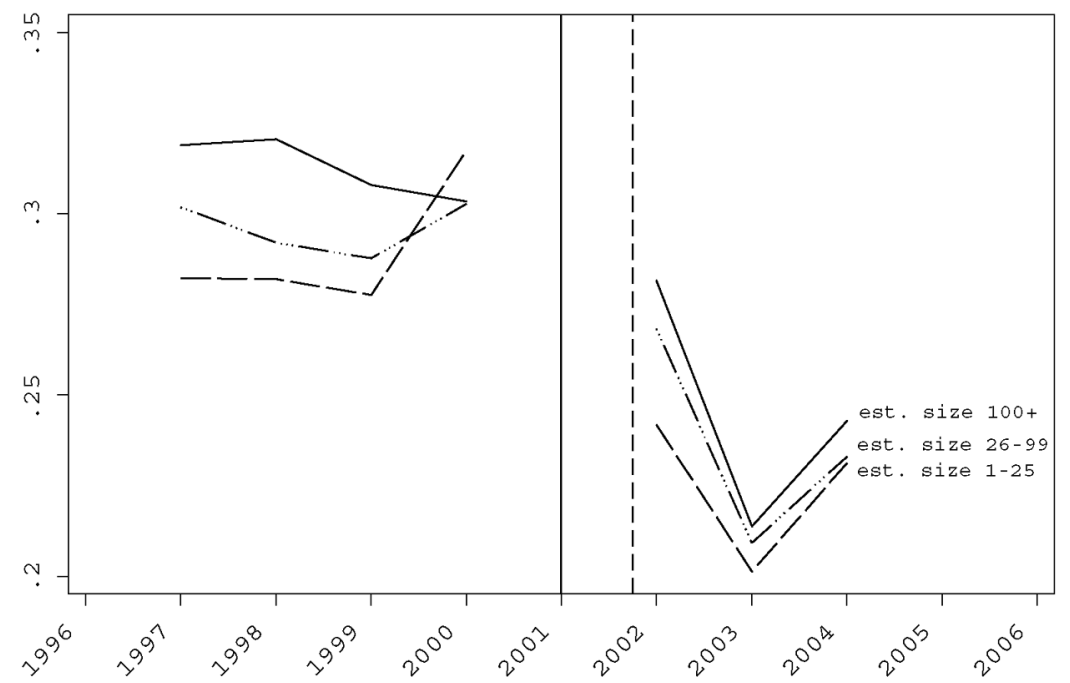

Fig. 11. Poaching and establishment size. The fraction of new hires coming from other employers, by establishment size category. The solid (dashed) vertical line indicates NBER peaks (troughs). Source: SIPP and authors' calculations. 


\section{The Cyclical Dynamics of Wages and Earnings}

Third, and finally, we revisit the age-old issue of real wage cyclicality. Our hypothesis is that the evolution of employment by firm size and job-to-job transitions fuel aggregate wage growth. Publicly available data from the BLS Current Employment Statistics on average monthly real (weekly and hourly) earnings show, after standard HP detrending, a behavior similar to that of the other variables that we have studied so far: flat in the first part of an expansion and sharply increasing later on. This occurs in every complete U.S. business cycle in 1964-2006, with the only exception of the 1980s, when a sharp decline in real wages of unskilled workers gave rise to the well-known increase in wage inequality. We do not report these raw data, but in order to isolate the pure cyclical effect, we first attempt to control for composition effects in employment over a suitably long time period.

We gather information on earnings, hours, and demographics from the Merged Outgoing Rotations of the monthly CPS, starting in 1982 when they became available. We take percentage wage growth over subsequent 12 months for the same individual as the object to be explained in order to eliminate fixed effects in wage levels. Results for weekly earnings rather than hourly wages are very similar. We regress wage growth on many demographics to capture also composition effects by observables in wage changes. Since we have only two observations on wage levels and one on wage growth per individual, we cannot estimate individual fixed effects in growth rates. Finally, we plot the median residual from this regression month by month in figure 12 . We also plot the 52nd percentile of the residual distribution in order to take into account the proportion of top-coded earnings (between $0 \%$ and $2 \%$ per month), which create a spurious mass of zero or very low wage growth. The unemployment rate (again in deviation from HP trend) is also superimposed to gauge cyclicality. Relative to the first month, January 1982, rescaled to zero, unexplained wage growth is positive in the late 1980s and especially late 1990s, when the labor market was tight according to our definition, and negative in early 1990s and 2000s, when it was slack.

A breakdown of the mean wage series by establishment size categories can be obtained from the CBP data. This is reported in figure 13 (once again the CBP data start only in 1990). This figure is remarkable in at least two respects. First, mean wages are monotonically increasing in establishment size at all dates. This is another rendition of the well-documented firm size-wage gap (see Oi and Idson [1999] for an 


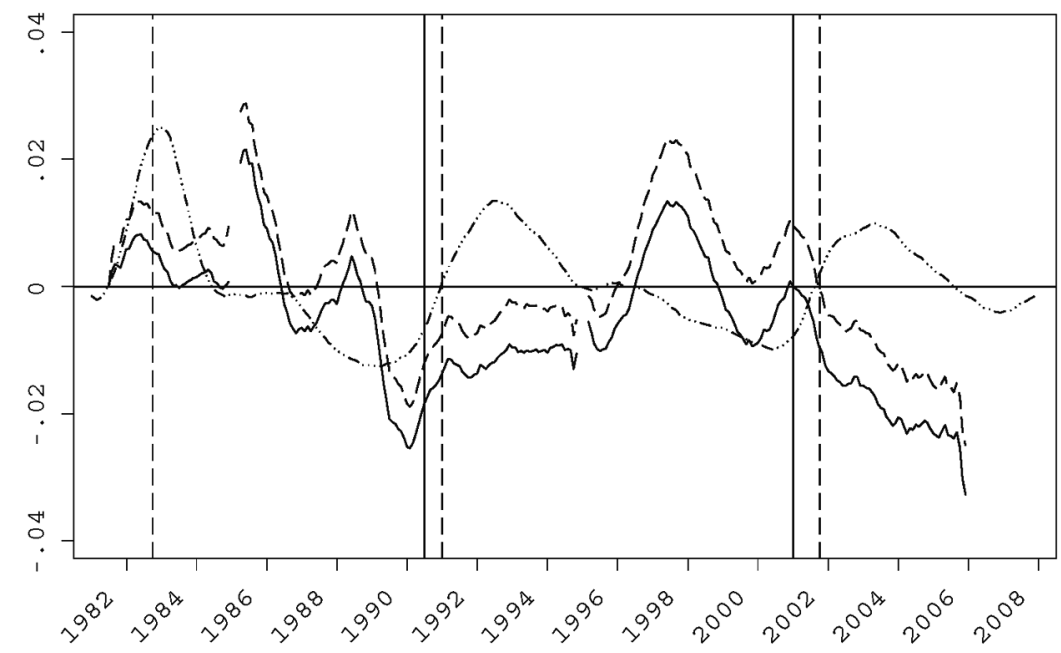

Fig. 12. Median and 52nd percentile of residual growth rate of individual hourly wages unexplained by employment composition effects. The solid line is the median wage, the dashed line is the 52nd percentile wage, and the dash-dot line is the unemployment rate. U.S. monthly data, all series MA smoothed. The solid (dashed) vertical line indicates NBER peaks (troughs). Source: CPS and authors' calculations.

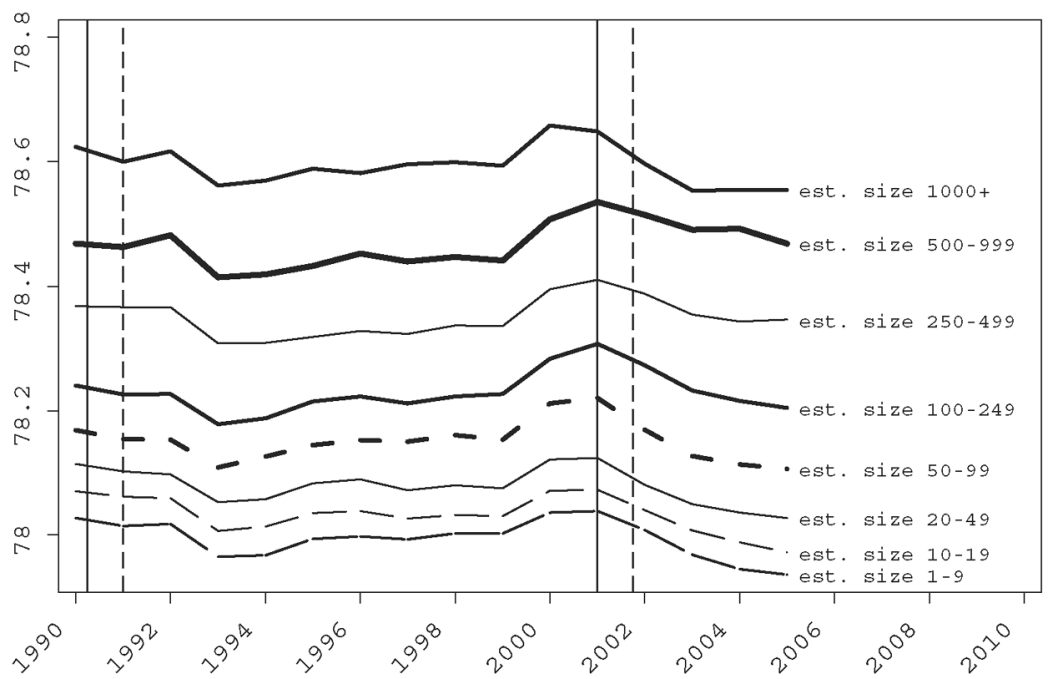

Fig. 13. Wages by establishment size. Detrended log wages by establishment size category. The solid (dashed) vertical line indicates NBER peaks (troughs). 
overview). ${ }^{17}$ Second, all wage profiles plotted in figure 13 are nearly parallel. In other words, the distribution of mean wages by establishment size shows no clear sign of collapsing or fanning out over time. As a consequence, the aggregate pattern of wage dynamics (and the associated wage "stickiness") holds roughly unchanged in each firm size category.

\section{E. Taking Stock of the Facts: A Hypothesis on Aggregate Labor Market Fluctuations}

All in all, EE rates, wages, and employment in large firms appeared to comove: sluggish early in the last two expansions and brisk in the late stages of the 1990s expansion (and possibly of the current one, since late 2005). Our facts appear to plainly contradict a well-established set of facts regarding the sensitivity of small firms to cyclical conditions and monetary shocks. In a very influential paper, Gertler and Gilchrist (1994) present evidence that small firms, which they argue are more credit constrained, are more sensitive to recessions and to Romer and Romer (1989) monetary policy shocks. They define size in terms of sales and use a quarterly time series of the manufacturing sector, the Quarterly Financial Report for Manufacturing Corporations, since 1958. The data set is confined to manufacturing, has nominal sales as a size variable (hence raising the issue of industry-specific price indexes within manufacturing), and is not immune to the reclassification bias, leading Gertler and Gilchrist to make an ingenious yet ad hoc correction. In addition, their conclusion holds for Romer shocks, which are notoriously controversial, and not for NBER-dated recessions. Of the six recessions in their sample period, only in 1970 one sees a clear collapse in the growth rate of sales at small firms relative to large ones (their fig. I), and the opposite occurs in 1982. The other four episodes appear fairly neutral. ${ }^{18}$ All in all, we believe that the picture of the whole economy over NBER-dated cycles for the postwar period, after one controls for reclassification, is likely to be much closer to our conclusions than to those of Gertler and Gilchrist. In the period we cover, since the late 1980s, our facts about firm size and growth are very firmly established.

Surely the facts that we have highlighted pertain only to the last two expansions and as such are not enough to establish an empirical regularity. Yet, practitioners of macroeconomic forecasting have already identified, at least qualitatively, some cyclical pattern of job creation by employer size. ${ }^{19}$ Commercial forecasters rely not only on some of the statistics produced by the federal government that we exploit here 
but also on occasional private surveys of businesses, of inferior statistical quality but often going back in time much longer. Although we do not put much weight on an established conventional wisdom of commercial forecasters, at least it does not contradict the possibility that we may, indeed, have identified new business cycle stylized facts. We stress, however, that our search for facts has been guided mostly by our theoretical hypothesis mentioned in the introduction and fully spelled out below. Our conceptual framework will provide both an interpretation of the facts and a motive to look further for additional facts that might appear prima facie unrelated and that were previously unknown to academic or commercial economists. Examples are the evolution of the firm size distribution in BED at a quarterly frequency and the composition of new hires by size of new employers from SIPP.

Whatever their actual degree of regularity, our new facts, taken together, suggest the following pattern for at least the last two decades. Early in an expansion, the large pool of unemployed workers sustains firms' monopsony power. Wages remain low, firms hire mostly from unemployment, and relatively few workers quit from job to job. As the reservoir of unemployment dries up, more and more of the new hires arrive from other jobs. As poaching becomes the main source of hiring, average wages and earnings rise and the EE rate picks up. If workers quit mostly from small, low-paying firms to large, high-paying firms, the growth in the employment of large firms will be fueled by the stock of employment at small firms, which takes some time to replenish after a recession. Hence, employment at small firms rises faster and peaks earlier than at large firms. The erosion in firms' monopsony power reduces average markups several years into an expansion, potentially creating favorable conditions for a new recession.

This pattern is reminiscent of Okun's (1973) idea of cyclical upgrading (see Bils and McLaughlin [2001] for a recent new interpretation), a cross-industry pattern whereby labor reallocates itself from low- to high-paying industries. Instead the phenomena that we emphasize in this section hold within industries (fig. 9) and not across. This is surely worth noticing, although it does not pose a particular problem for our proposed interpretation, which seems to apply equally well to many industries. It is in fact natural to expect that, if workers have any significant attachment to an industry, then they should upgrade within industries more than across.

While our proposed description of labor market dynamics might appear plausible and intuitive, it remains to verify whether in fact it can be consistent with equilibrium behavior. To this purpose, in the following 
sections we study the transitional dynamics of the Burdett-Mortensen wage-posting model with heterogeneous firms. ${ }^{20}$ The Burdett-Mortensen model is the canonical framework for the analysis of frictional labor markets that explicitly addresses firm size, job-to-job quits, wage dispersion, and unemployment, the four key ingredients of our facts. We are not aware of any other model that can account for all four.

\section{The Economy}

Time is continuous. The labor market is populated by a unit mass of workers who can be either employed or unemployed. Owing to search frictions, unemployed workers can sample job offers sequentially only at some finite Poisson rate $\lambda_{0}>0$. Employed workers are allowed to search on the job and face a sampling rate of job offers of $\lambda_{1}>0$. Employed workers lose their jobs and become unemployed at rate $\delta>0$. All workers are ex ante identical: they are infinitely lived, risk neutral, and equally capable at any job; they discount future payoffs at rate $\rho$; and they attach a common lifetime value of $U_{t}$ to being unemployed at date $t$.

Workers face a measure $N$ of active firms operating constant return technologies with heterogeneous productivity levels $p \sim \Gamma(\cdot)$ among firms, with support $[p, \bar{p}]$. Firms are also infinitely lived and risk neutral and discount future payoffs at rate $r$. We will assume, as standard, $r=\rho$, but we will maintain the separate notation to help the reader distinguish between workers' and firms' objectives functions.

For quantitative reasons that will become clear below, we assume that the sampling of firms by workers is not uniform, in that a type $p$ firm has a sampling weight of $q(p)>0$. Sampling weights are normalized in such a way that their cumulated sum $\Phi(p):=\int_{p}^{p} q(x) d \Gamma(x)$ is a (sampling) cumulative distribution function (cdf), that is, $\Phi(\bar{p})=1$. The sampling density of a type $p$ firm is therefore $\varphi(p):=q(p) \gamma(p)$. This naturally encompasses the conventional case of uniform sampling, which has $q(p)=1$ for all $p$. As we shall see later in the analysis, however, a plausible calibration requires that $q(p)$ be increasing in $p .^{21}$

At some initial date, which we normalize to be time 0 , each firm of a given type $p$ commits to a wage profile $\left\{w_{t}(p)\right\}_{t \in[0,+\infty)}$ to be paid to all its workers over the infinite future. We generalize the Burdett-Mortensen restrictions placed on the set of feasible wage contracts to a non-steadystate environment by preventing firms from making wages contingent on anything other than calendar time. ${ }^{22}$

Any such profile $\left\{w_{t}(p)\right\}_{t \in[0,+\infty)}$ offered by any type $p$ firm yields a continuation value of $V_{t}(p)$ to any worker employed at that firm at 
any date $t$. The (time-varying) sampling distribution of job values is denoted as $F_{t}(\cdot)$, and its relationship to the sampling distribution of firm types $\Phi(\cdot)$ will be discussed momentarily. Because from the workers' viewpoint jobs are identical in all dimensions but the wage profile, employed job seekers quit into higher-valued jobs only. This gradual selfselection of workers into better jobs implies that the distribution of job values in a cross section of workers-which will be denoted as $G_{t}(\cdot)$ differs from the sampling distribution $F_{t}(\cdot)$.

\section{Equilibrium}

\section{A. The Contract-Posting Problem}

A firm of productivity $p$ posts a wage profile over an infinite horizon to solve the following problem:

$$
\Pi_{0}\left(L_{0}(p) ; p\right)=\max _{\left\{w_{t}\right\}} \int_{0}^{+\infty}\left(p-w_{t}\right) L_{t}(p) e^{-r t} d t
$$

subject to

$$
\begin{gathered}
\rho V_{t}(p)=\dot{V}_{t}(p)+w_{t}-\delta\left[V_{t}(p)-U_{t}\right]+\lambda_{1} \int_{V_{t}(p)}^{+\infty}\left[x-V_{t}(p)\right] d F_{t}(x), \\
\dot{L_{t}}(p)=-\left[\delta+\lambda_{1} \bar{F}_{t}\left(V_{t}(p)\right)\right] L_{t}(p)+\frac{q(p)}{N}\left[\lambda_{0} u_{t}+\lambda_{1}\left(1-u_{t}\right) G_{t}\left(V_{t}(p)\right)\right],
\end{gathered}
$$

and

$$
w_{t} \geq \underline{w},
$$

where (with a slight notational abuse) $L_{t}(p)$ denotes a type $p$ firm's workforce at date $t_{,}^{23} \underline{w}$ is the exogenous institutional minimum wage, $U_{t}$ is the workers' lifetime value of unemployment, and $\bar{F}_{t}(\cdot)=1-F_{t}(\cdot)$ designates the survivor function associated with $F_{t}(\cdot)$. When solving $(1)$, the typical firm of productivity $p$ is also constrained by its given initial size $L_{0}(p)$.

The firm's problem has two state variables that the firm controls through the wage. First, the chosen path of wages translates through the Hamilton-Jacobi-Bellman equation (2) into a value $V_{t}(p)$ for the worker of employment at that type $p$ firm. The worker's opportunity cost $\rho V_{t}(p)$ equals the capital gain plus the flow wage minus the capital loss when the match is destroyed exogenously at rate $\delta$, plus the capital gain that occurs at rate $\lambda_{1} \bar{F}_{t}\left(V_{t}(p)\right)$ when the worker receives an offer that 
also turns out to provide him with a higher value. This offer is drawn from the endogenous offer distribution $F_{t}(\cdot)$, which is the cross-section distribution at time $t$ of all such values offered by other firms.

In turn, the value $V_{t}(p)$ offered by a type $p$ firm translates into inflows and outflows of workers. The only friction in the model is search, so the boundaries of the firm are defined by attrition, retention, and hiring. Equation (3) describes the evolution of the firm's employment. Following standard practice, we impose a law of large numbers at the individual firm's level and we treat the evolution of firm size as deterministic, although it is the result of various random events. These include separations-both exogenous at rate $\delta$ and endogenous at rate $\lambda_{1} \bar{F}_{t}\left(V_{t}(p)\right)$ when a worker receives a better offer-that reduce employment and accessions both from unemployment (at rate $\lambda_{0}$ ) and from other firms that are paying their workers less than $V_{t}(p)$. For future reference, notice the role played by the unemployment rate $u_{t}$ in (3). It provides an exogenous inflow of workers that does not depend on the firm's wage policy. Therefore, the firm's incentives to post a costly, high wage depend on how easy or difficult it is to hire from unemployment, as opposed to poaching from other firms, as well as on retention needs given current size.

At the individual firm's level, the sampling and cross-sectional distributions of job values $F_{t}(\cdot)$ and $G_{t}(\cdot)$ are given macroeconomic quantities that no individual firm can affect with its choice. Given all of a firm's choices of wages and the implied worker values $V_{t}(p)$ and firm sizes $L_{t}(p)$, they are defined by

$$
F_{t}(W)=\int_{\underline{p}}^{\bar{p}} \square\left\{V_{t}(x) \leq W\right\} q(x) d \Gamma(x)
$$

and

$$
G_{t}(W)=\frac{\int_{\underline{p}}^{\bar{p}} L_{t}(x) \square\left\{V_{t}(x) \leq W\right\} d \Gamma(x)}{\int_{\underline{p}}^{\bar{p}} L_{t}(x) d \Gamma(x)},
$$

where $\square\{\cdot\}$ is an indicator function. Notice that both are normalized to be proper cdf's. Also notice an important restriction that was kept implicit so far: the definitions in (5) and (6) are valid only in symmetric equilibria in which there is no dispersion in firm size conditional on $p$ (i.e., $p \mapsto V_{t}(p)$ and $p \mapsto L_{t}(p)$ are well-defined mappings for all $t$ ). We will limit our attention to such equilibria. 
Similarly, a single firm cannot affect the value of unemployment, which solves the Hamilton-Jacobi-Bellman equation: ${ }^{24}$

$$
\rho U_{t}=\dot{U}_{t}+b+\lambda_{0} \int_{U_{t}}^{+\infty}\left(x-U_{t}\right) d F_{t}(x),
$$

with $b$ denoting the income flow in unemployment, or the unemployment rate $u_{t}$, which solves

$$
\dot{u}_{t}=\delta\left(1-u_{t}\right)-\lambda_{0} u_{t},
$$

with

$$
u_{0}=1-N \int_{\underline{p}}^{\bar{p}} L_{0}(x) d \Gamma(x)
$$

given.

Before we move on to solving (1), we should clarify that our formulation of the contract-posting game and the firm's best-response problem contains the assumption that a firm must pay all its workers the same wage, irrespective of when they were hired, where they were hired from, and the outside offers that some of them may have received. In particular, the firm does not renege on its promised wage, cannot condition the wage on tenure or received outside offers, and more generally does not respond to outside offers to its employees, but lets them go if they are offered more. ${ }^{25}$

Finally, as we are solving for the equilibrium of a dynamic game between firms and workers, we need to spell out out-of-equilibrium play. First, firms commit to wage offers vis-à-vis workers. They will be tempted to renege and to offer their employees just the value of unemployment, leading again to the Diamond (1971) paradox. Possible reputational mechanisms to support this commitment have been explored, and we maintain this assumption. Formally, the wage that the firm plans at time 0 is the same wage that enters the worker's HamiltonJacobi-Bellman equation (2) at any future date $t>0$. Second, the firm takes as given the paths of distribution of its competitor's strategies $F_{t}$ and $G_{t}$. That is, no unilateral deviation can change the distributions of offered and earned values in the market. The zero measure of a firm is necessary but not sufficient for this. If an individual deviation was publicly observed, it could serve as a coordination device for a positive measure set of other firms to respond. Hence, we assume that wage offers are observed only by the workers who receive them. Any worker could spread the news of the past deviation only to the at most countable 
set of firms it comes in contact with in the future. Under these two assumptions, the solution to the wage path posting problem is time consistent, by the principle of optimality.

\section{B. Optimality Conditions}

The current-value Hamiltonian of problem (1) is defined by

$$
\begin{aligned}
\mathcal{H}_{t}(p)= & \left(p-w_{t}\right) L_{t}(p)+m_{t}(p)\left(w_{t}-\underline{w}\right) \\
& +\pi_{t}(p)\left\{-\left[\delta+\lambda_{1} \bar{F}_{t}\left(V_{t}(p)\right)\right] L_{t}(p)+\frac{q(p)}{N}\left[\lambda_{0} u_{t}\right.\right. \\
& \left.\left.+\lambda_{1}\left(1-u_{t}\right) G_{t}\left(V_{t}(p)\right)\right]\right\}+v_{t}(p)\{[\rho+\delta \\
& \left.\left.+\lambda_{1} \bar{F}_{t}\left(V_{t}(p)\right)\right] V_{t}(p)-\lambda_{1} \int_{V_{t}(p)}^{+\infty} x d F_{t}(x)-w_{t}-\delta U_{t}\right\},
\end{aligned}
$$

where $v_{t}(p)\left(\pi_{t}(p)\right)$ is the costate associated with $V_{t}(p)\left(L_{t}(p)\right)$ and $m_{t}(p) \geq 0$ is the Lagrange multiplier associated with the minimum wage constraint (4).

Optimality conditions are

$$
\begin{gathered}
v_{t}(p)=-L_{t}(p)+m_{t}(p), \\
\dot{v}_{t}(p)=r v_{t}(p)-\left[\rho+\delta+\lambda_{1} \bar{F}_{t}\left(V_{t}(p)\right)\right] v_{t}(p) \\
-\lambda_{1} f_{t}\left(V_{t}(p)\right) L_{t}(p) \pi_{t}(p)-\frac{\lambda_{1} q(p)}{N}\left(1-u_{t}\right) g_{t}\left(V_{t}(p)\right) \pi_{t}(p), \\
\dot{\pi}_{t}(p)=\left[r+\delta+\lambda_{1} \bar{F}_{t}\left(V_{t}(p)\right)\right] \pi_{t}(p)-p+w_{t}(p), \\
m_{t}(p) \geq 0, \quad w_{t}(p) \geq \underline{w}, \quad m_{t}(p)\left[w_{t}(p)-\underline{w}\right]=0,
\end{gathered}
$$

and

$$
\lim _{t \rightarrow+\infty} e^{-r t} \pi_{t}(p) L_{t}(p)=\lim _{t \rightarrow+\infty} e^{-r t} v_{t}(p)\left[V_{t}(p)-U_{t}\right]=0
$$

Supplementing this latter set of conditions with the state equations (3), (7), and (8), we obtain a system of partial differential equations characterizing the solution to an individual firm's maximization problem for a given path of sampling distributions $\left\{F_{t}(\cdot)\right\}_{t \in[0,+\infty)}$. Given a solution to that system, the optimal wage path can be retrieved using (2). The main difficulty, however, lies in characterizing the equilibrium $\left\{F_{t}(\cdot)\right\}_{t \in[0,+\infty)}$, that is, the path of sampling distributions that is consistent with the 
above dynamic system simultaneously for the whole population of firms. This task will be carried out in the following subsections. Before we turn to that, however, it is worth spelling out some economic interpretation of the above optimality conditions.

As usual in economic applications of optimal control, the costate variables $\pi_{t}(p)$ and $\nu_{t}(p)$ are interpreted as the imputed unit value of the corresponding state variable at date $t$ (i.e., $L_{t}(p)$ and $V_{t}(p)$, respectively). Note that $v_{t}$ is negative since it is costly for any firm to transfer a higher value to its employees.

Equation (12) describes the dynamics of the firm's shadow value of its marginal employee. Notice that the overall rate at which the firm will discount that value is the sum of sheer time discounting (at the interest rate $r$ ) plus a "depreciation rate" of $\delta+\lambda_{1} \bar{F}_{t}\left(V_{t}(p)\right)$ reflecting future match dissolution, through either job destruction or the worker quitting. With that in mind, equation (12) has a straightforward assetpricing-type interpretation whereby the firm's marginal employee is viewed as an asset priced at $\pi_{t}(p)$. The annuity value of the marginal employee, $\left[r+\delta+\lambda_{1} \bar{F}_{t}\left(V_{t}(p)\right)\right] \pi_{t}(p)$, must then equal the return on the corresponding asset, which is the sum of a dividend term $p-w_{t}(p)$ plus a capital gain term $\dot{\pi}_{t}(p)$.

Equation (11) next describes the dynamics of the firm's shadow value of a unit increase in the value it yields to its employees. It can also be viewed as an asset-pricing equation (even though in this case we are really talking about a cost since $v_{t}(p)$ is negative) whereby the annuity value $r v_{t}(p)$ is set equal to the capital gain $\dot{v}_{t}(p)$ plus a dividend term that represents the net benefit of increasing $V_{t}(p)$ by one unit through the effect of that increase on future profit streams (the effect of such an increase on current profits being nil). This latter term has two components, the first of which is

$$
\pi_{t}(p) \cdot \frac{\partial \dot{L_{t}}(p)}{\partial V_{t}(p)}=\pi_{t}(p) \cdot\left[\lambda_{1} f_{t}\left(V_{t}(p)\right) L_{t}(p)+\frac{\lambda_{1} q(p)}{N}\left(1-u_{t}\right) g_{t}\left(V_{t}(p)\right)\right]
$$

and represents the future benefits of a larger workforce achieved through the higher retention and hiring rates resulting from the marginal increase in the value offered to workers. The second dividend component (in fact a cost since it is negative),

$$
\nu_{t}(p) \cdot \frac{\partial \dot{V}_{t}(p)}{\partial V_{t}(p)}=v_{t}(p)\left[\rho+\delta+\lambda_{1} \bar{F}_{t}\left(V_{t}(p)\right)\right]
$$

has a somewhat less tangible interpretation. It measures the cost that the firm incurs through the change in the capital gain achieved by its 
workers caused by a marginal increase in the value currently transferred to them, $V_{t}(p)$. This change in capital gain is proportional to the workers' overall discount rate, which again results from a combination of pure time discounting (at rate $\rho$ ) and a risk of leaving the match (rate $\delta+$ $\lambda_{1} \bar{F}_{t}\left(V_{t}(p)\right)$ ). A possible way to interpret this is to view an employer's commitment to transferring a certain value to its workers as that employer running up a debt to its employees. The consequence of a marginally higher current stock of debt is to increase the debt burden and speed up debt accumulation by an amount proportional to the interest paid on that debt, which here is indicated by the workers' discount rate.

Finally, equation (10) simply reflects the optimal balance between the instantaneous cost of increasing the current posted wage by $\$ 1-i t$ adds $\$ L_{t}(p)$ to the current wage bill, plus possibly the instantaneous benefit of slackening the minimum wage constraint that is given by the Lagrange multiplier $m_{t}(p)$-and the future benefit of doing so, $-v_{t}(p)$. The debt analogy can be used for interpretation here as well: the future benefit of raising the wage at date $t$ comes about through a reduced speed of debt accumulation (a smaller $\dot{V}_{t}(p)$ ), which follows from a higher installment (a higher wage) paid at date $t$.

\section{Rank-Preserving Equilibria}

All further formal analysis of the model will build on the following definition.

Definition 1 (Rank-preserving equilibrium). A rank-preserving equilibrium (RPE) is a dynamic equilibrium in which firms post values that are strictly increasing in $p$ for all $t$.

A direct consequence of the above definition is that in an RPE workers rank firms according to productivity at all dates. The following two properties hold true at all dates under the RP assumption:

$$
F_{t}\left(V_{t}(p)\right) \equiv \Phi(p) \quad \text { and } \quad\left(1-u_{t}\right) G_{t}\left(V_{t}(p)\right)=N \int_{\underline{p}}^{p} L_{t}(x) d \Gamma(x) .
$$

At all points in time, the fraction of firms that offer a value less than the $V_{t}(p)$ offered by firm $p$ equals the (sampling-weighted) proportion of firms that are less productive than $p$. And the measure of employed workers who are paid less than $V_{t}(p)$ equals the measure of employment at firms that are less productive than $p$. In addition to considerably simplifying equilibrium determination (see below), the RP assumption is theoretically appealing for at least two reasons. First, it parallels a well-known property 
of the static equilibrium characterized by Burdett and Mortensen, which is to have a unique equilibrium in which workers rank firms according to productivity. Second, RPEs feature constrained-efficient labor reallocation at all dates: if workers consistently rank more productive firms higher than less productive ones, then job-to-job moves will always be up the productivity ladder. $^{26}$ Under some relatively mild conditions on the initial distribution of employment, equilibrium must be RP, as we establish in Moscarini and Postel-Vinay (2008), to which we refer the interested reader.

Let us consider the stock of workers employed at a firm of type $p$ or less, $Q_{t}(p)=\int_{p}^{p} L_{t}(x) d \Gamma(x)$. In an RPE (assuming one exists), those firms hire workers from unemployment and lose workers to their more productive competitors (firms of type higher than $p$ ). The stock of workers under consideration thus evolves according to ${ }^{27}$

$$
\int_{\underline{p}}^{p} \dot{L_{t}}(x) d \Gamma(x)=\frac{\lambda_{0} u_{t}}{N} \Phi(p)-\left[\delta+\lambda_{1} \bar{\Phi}(p)\right] \int_{\underline{p}}^{p} L_{t}(x) d \Gamma(x),
$$

which is a linear ordinary differential equation in $Q_{t}(p)$ for given $p$. Solving it for $Q_{t}(p)$, differentiating the solution with respect to $p$, and equating it to $Q_{t}^{\prime}(p)=L_{t}(p) \gamma(p)$, we obtain a closed-form expression for the workforce of any type $p$ firm:

$$
\begin{aligned}
L_{t}(p)= & e^{-\left[\delta+\lambda_{1} \bar{\Phi}(p)\right] t}\left\{L_{0}(p)+\lambda_{1} t q(p) \int_{\underline{p}}^{p} L_{0}(x) d \Gamma(x)\right. \\
& \left.+\frac{\lambda_{0} q(p)}{N} \int_{0}^{t}\left[1+\lambda_{1}(t-s) \Phi(p)\right] u_{s} e^{\left[\delta+\lambda_{1} \Phi(p)\right] s} d s\right\} .
\end{aligned}
$$

The steady-state version of (15),

$$
L_{\infty}(p)=\frac{\delta \lambda_{0}\left(\delta+\lambda_{1}\right) q(p)}{N\left(\delta+\lambda_{0}\right)\left[\delta+\lambda_{1} \bar{\Phi}(p)\right]^{2}},
$$

motivates the introduction of sampling weights. In any RPE the most (least) productive firm always wins (loses) against poachers, namely, $\bar{\Phi}(\bar{p})=0=1-\bar{\Phi}(p)$. Since the RP property implies that size and productivity are perfectly correlated in steady state, from (15) the steadystate size ratio of the largest to the smallest firm in the market in units of (nonnormalized) employment is

$$
\frac{L_{\infty}(\bar{p})}{L_{\infty}(\underline{p})}=\left(1+\frac{\lambda_{1}}{\delta}\right)^{2} \frac{q(\bar{p})}{q(\underline{p})} .
$$

With uniform sampling $(q(p) \equiv 1$ throughout), this ratio would equal $\left[1+\left(\lambda_{1} / \delta\right)\right]^{2}$, which is in the order of 25-30 given standard estimates 
of $\lambda_{1}$ and $\delta$. Now of course the data counterpart of that size ratio is virtually infinite. More generally, it appears that the Burdett-Mortensen model requires a sampling distribution that is very heavily skewed toward high-productivity firms in order to replicate the observed distribution of firm sizes. We discussed several possible interpretations/formalizations of these sampling weights. This skew may be interpreted as a measure of the inability of search frictions alone to generate a plausible firm size distribution. Alternative forces that may contribute to shaping the size distribution include credit constraints (Cooley and Quadrini 2001) and industry-specific human capital accumulation (Rossi-Hansberg and Wright 2007). We note, however, that our frictions-based approach has the distinct advantage of generating observable implications in terms of job-to-job quit rates by workers, wages within and across size classes, which add considerable empirical discipline to the theoretical exercise. Furthermore, exisiting theories of firm size have been so far silent on aggregate dynamics.

Before going any further into characterizing RPE, we should notice that the analysis of firm size and employment dynamics carried out in this subsection would apply to any job ladder model in which a similar concept of RPE can be defined. Indeed nothing in the dynamics of $L_{t}$ or $u_{t}$ depends on the particulars of the wage-setting mechanism, as long as this is such that employed job seekers move from lower-ranking into higher-ranking jobs in the sense of a time-invariant ranking. Therefore, this model's predictions about everything relating to firm sizes are in fact much more general than the wage-posting assumption retained in the Burdett-Mortensen model.

\section{Rank-Preserving Equilibria: Characterization}

We now go back to the dynamical system characterizing the behavior of the typical individual firm and analyze it in an RPE. The system in question comprises the set of optimality conditions (10)-(14) plus the set of state equations (3), (2), and (8). We first focus on intervals of time in which the solution is interior, that is, such that $m_{t}(p)=0$ and $w_{t}(p)>\underline{w}$. In this situation $v_{t}(p)=-L_{t}(p)$. Substitution of (10) into (11) and combination with (3) then yields

$$
\begin{gathered}
\frac{q(p)}{N}\left[\lambda_{0} u_{t}+\lambda_{1}\left(1-u_{t}\right) G_{t}\left(V_{t}(p)\right)\right]= \\
\lambda_{1} \pi_{t}(p)\left[f_{t}\left(V_{t}(p)\right) L_{t}(p)+\frac{q(p)}{N}\left(1-u_{t}\right) g_{t}\left(V_{t}(p)\right)\right] .
\end{gathered}
$$


This latter equation reflects a balance between the firm's present-value cost and benefit of marginally changing its posted value at date $t$. The right-hand side of (17) equals $\pi_{t}(p) \cdot\left[\partial \dot{L}_{t}(p) / \partial V_{t}(p)\right]$ and clearly reflects the benefit of offering a marginally higher value stemming from the larger workforce achieved through the implied higher retention and hiring rates. To see how the left-hand side of (17) reflects the cost of a marginal increase in the value transferred to workers, it may help again to view $V_{t}(p)$ as an employer's debt to each of its employees. The (net) interest paid on that debt equals the workers' overall discount rate, $\rho+\delta+\lambda_{1} \bar{F}_{t}\left(V_{t}(p)\right)$, less the firm's discount (or interest) rate $r$. A unit increase in the value offered to all of the firm's employees then adds $L_{t}(p)$ to the firm's stock of debt. The marginal cost of such an addition to the stock of debt is an increase in the debt burden, which in turn results from the net interest paid on that debt being raised by $[\rho-r+\delta+$ $\left.\lambda_{1} \bar{F}_{t}\left(V_{t}(p)\right)\right] L_{t}(p)$ plus an extrinsic expansion/contraction term $\dot{L_{t}}(p)$ reflecting the fact that the stock of debt is by nature indexed to workforce size. The sum of these latter two terms is equal to equation (17)'s lefthand side (under the assumption that $r=\rho$ ).

Next define the shadow value to the firm-worker match (rather than to the firm) of the marginal unit of labor as $\mu_{t}(p)=\pi_{t}(p)+V_{t}(p)$. Then a combination of (2) and (12) yields

$$
\dot{\mu}_{t}(p)=\left[r+\delta+\lambda_{1} \bar{F}_{t}\left(V_{t}(p)\right)\right] \mu_{t}(p)-\lambda_{1} \int_{V_{t}(p)}^{+\infty} x d F_{t}(x)-\delta U_{t}-p,
$$

which is supplemented by the transversality condition $\lim _{t \rightarrow+\infty} e^{-r t} L_{t}(p)$ $\times\left[\mu_{t}(p)-U_{t}\right]=0$, obtained from adding the two conditions in (14) together and substituting the first-order condition (10). Interpretation of equation (18) is once again based on straightforward asset-pricing-type arguments, and we shall therefore not dwell on it.

The RP assumption finally changes the system (17)-(18) into

$$
\begin{gathered}
{\left[\frac{\lambda_{0} u_{t}}{N}+\lambda_{1} \int_{\underline{p}}^{p} L_{t}(x) d \Gamma(x)\right] V^{\prime}(p)=2 \lambda_{1} \gamma(p) L_{t}(p) \pi_{t}(p),} \\
\dot{\mu}_{t}(p)=\left[r+\delta+\lambda_{1} \Phi(p)\right] \mu_{t}(p)-\lambda_{1} \int_{p}^{+\infty} V_{t}(x) d \Phi(x)-\delta U_{t}-p,
\end{gathered}
$$

and

$$
\lim _{t \rightarrow+\infty} e^{-r t} L_{t}(p)\left[\mu_{t}(p)-U_{t}\right]=0
$$


Differentiation of (20) with respect to $p$ yields (primes denote differentiation with respect to $p$ and dots denote time differentiation)

$$
\dot{\mu}_{t}^{\prime}(p)=\left[r+\delta+\lambda_{1} \bar{\Phi}(p)\right] \mu_{t}^{\prime}(p)+\lambda_{1} \gamma(p) q(p)\left[V_{t}(p)-\mu_{t}(p)\right]-1 .
$$

This, together with (19), gives the following system of two partial differential equations in $\left(\mu_{t}^{\prime}(p), \pi_{t}(p)\right)$ :

$$
\begin{aligned}
\dot{\mu}_{t}^{\prime}(p) & =\left[r+\delta+\lambda_{1} \bar{\Phi}(p)\right] \mu_{t}^{\prime}(p)-\lambda_{1} \gamma(p) q(p) \pi_{t}(p)-1, \\
\mu_{t}^{\prime}(p) & =\pi_{t}^{\prime}(p)+\frac{2 \lambda_{1} \gamma(p) L_{t}(p)}{\left(\lambda_{0} u_{t} / N\right)+\lambda_{1} \int_{\underline{p}}^{p} L_{t}(x) d \Gamma(x)} \pi_{t}(p) .
\end{aligned}
$$

This system can be solved numerically, subject to boundary conditions in time, given by the steady-state solution to (23),

$$
\begin{aligned}
\mu_{\infty}^{\prime}(p) & =\frac{1+\lambda_{1} \gamma(p) q(p) \pi_{\infty}(p)}{r+\delta+\lambda_{1} \bar{\Phi}(p)} \\
\pi_{\infty}(p) & =\frac{\left[\delta+\lambda_{1} \bar{\Phi}(p)\right]^{2}}{r+\delta+\lambda_{1} \bar{\Phi}(p)}\left\{\int_{\underline{p}}^{p} \frac{d x}{\left[\delta+\lambda_{1} \bar{\Phi}(x)\right]^{2}}+\frac{\pi_{\infty}(\underline{p})\left(r+\delta+\lambda_{1}\right)}{\left(\delta+\lambda_{1}\right)^{2}}\right\}
\end{aligned}
$$

and in productivity space. Standard arguments prove that the lowesttype firms have no reason to pay more than the minimum wage: type $p$ firms can hire only from unemployment and lose workers to poachers anyway, so trying to prevent poaching by raising wages is pointless for those firms in an RPE. While this implies that the minimum wage constraint (4) will bind at all dates for the lowest-type firm, it also implies that the following (time-invariant) boundary conditions are satisfied:

$$
\pi_{t}(\underline{p}) \equiv \frac{\underline{p}-\underline{w}}{r+\delta+\lambda_{1}} \quad \text { and } \quad \mu_{t}^{\prime}(\underline{p}) \equiv \frac{1+\lambda_{1} \gamma(\underline{p}) q(\underline{p}) \pi_{t}(\underline{p})}{r+\delta+\lambda_{1}},
$$

where the second condition is obtained by combining the first one with the $\dot{\mu}_{t}^{\prime}(p)$ equation in (23). These can be further simplified by imposing $p=\underline{w}$, a kind of free-entry condition holding throughout the adjustment toward the new steady state, which implies $\pi_{t}(p) \equiv 0$. The minimum productivity $p$ that can survive in the market is $\underline{w}$, since any firm with $p>\underline{w}$ can make positive profits by offering $\underline{w}$, and possibly even more by offering a higher wage, whereas no firm with $p<\underline{w}$ can ever make any profits.

Once (23) is solved for $\left(\mu_{t}^{\prime}(p), \pi_{t}(p)\right)$, wages can be retrieved from (12) (written under the RP assumption):

$$
w_{t}(p)=p-\left[r+\delta+\lambda_{1} \bar{\Phi}(p)\right] \pi_{t}(p)+\dot{\pi}_{t}(p),
$$


which has the following familiar steady-state solution:

$$
w_{\infty}(p)=p-\left[\delta+\lambda_{1} \Phi(p)\right]^{2}\left\{\int_{\underline{p}}^{p} \frac{d x}{\left[\delta+\lambda_{1} \bar{\Phi}(x)\right]^{2}}+\frac{\underline{p}-\underline{w}}{\left(\delta+\lambda_{1}\right)^{2}}\right\} .
$$

This is exactly the Burdett-Mortensen solution for the heterogeneous firm case (see eq. [47] in Burdett and Mortensen [1998]). This confirms that our contracts are consistent with the Burdett-Mortensen steadystate wage-posting equilibrium if the labor market is at a steady state. It is no longer the case off steady state, however: posting a time-invariant wage is not, in general, a firm's best response to all other firms posting time-invariant wages. $^{28}$

We now return to the minimum wage constraint. The only firm for which the minimum wage constraint (4) is binding at the steady state characterized above is the lowest-type firm, $p$. It may be the case, however, that the constraint temporarily binds for some higher-type firms over the transition to that steady state, in which case the economy no longer behaves according to (23) since $m_{t}(p)$ becomes strictly positive for some $p$ at some dates.

The appendix describes an algorithm that constructs an equilibrium in which $\underline{w}$ is allowed to temporarily bind for some firms (at the lower end of the $p$ distribution) with the restriction that it bind only over some initial period. In other words, any firm can choose to post the minimum wage for a while right after the occurrence of the productivity shock, but once it ceases to do so, it is not allowed to return to the minimum wage. Simulations, however, will prove that the minimum wage is offered only by the lowest- $p$ firms in equilibrium.

\section{Quantitative Analysis of Rank-Preserving Equilibria}

\section{A. Baseline Calibration}

A sampling distribution of firm types is first calibrated following the Bontemps, Robin, and Van den Berg (2000) procedure in such a way that the predicted steady-state wage distribution fits the business sector wage distribution observed in the CPS. Specifically, equation (16) implies that the steady-state cross-section cdf of wages, $G_{w}(\cdot)$ (say), is defined by

$$
\Phi(p)=\frac{\left(\delta+\lambda_{1}\right) G_{w}(w(p))}{\delta+\lambda_{1} G_{w}(w(p))} \Rightarrow \varphi(p)=\frac{\delta\left(\delta+\lambda_{1}\right) g_{w}(w(p)) w^{\prime}(p)}{\left[\delta+\lambda_{1} G_{w}(w(p))\right]^{2}} .
$$


Differentiation of equation (27) then yields

$$
w^{\prime}(p)=2 \lambda_{1} \varphi(p) \frac{p-w(p)}{\delta+\lambda_{1} \bar{\Phi}(p)} \quad \Rightarrow \quad p(w)=w+\frac{\delta+\lambda_{1} G_{w}(w)}{2 \lambda_{1} g_{w}(w)} .
$$

A lognormal distribution is fitted to a sample of wages from the 2006 CPS and then used to construct a sample of firm types using the above relationship. The sampling distribution $\Phi(\cdot)$ that rationalizes this sample in a steady state (and given values of $\delta$ and $\lambda_{1}$ ) is then retrieved using (28).

Once a sampling distribution has been obtained, the underlying distributions of firm types $\gamma(p)$ and sampling weights $q(p)$ are calibrated on the basis of the employment share/firm size relationship observed in BED data. ${ }^{29}$ That relationship is found to be well fitted by the following parametric form:

$$
\Gamma(p)=\left[\frac{1-e^{-\alpha_{1} G_{w}(w(p))}}{1-e^{-\alpha_{1}}}\right]^{\alpha_{2}}
$$

with $\alpha_{1}=8.0661$ and $\alpha_{2}=0.5843$. Sampling weights are finally retrieved as $q(p)=\varphi(p) / \gamma(p)$.

Apart from productivity dispersion, our baseline parameterization is explicated in table 1 . The time unit is 1 month. The value of $r=\rho$ reflects an annual discount rate of $5 \%$. The minimum wage is binding (in the sense that $p=\underline{w}$ ) since, being equal to 5 , it exceeds the lower support of the distribution of potential firm productivity levels, which was normalized at one (see the next subsection).

\section{B. Simulating an Expansion}

In order to simulate the economy's response to a one-time, permanent and unanticipated aggregate productivity shock, we further specify the model as follows. We assume that any firm's productivity parameter $p$ is the product of an aggregate productivity index $y$ (common to all firms) and a firm-specific random effect $\theta$. We further assume that there

\section{Table 1}

Baseline Parameterization

\begin{tabular}{ccccccc}
\hline \multicolumn{7}{c}{ Parameters (Postshock Monthly Values) } \\
\hline$r$ & $\delta$ & $\lambda_{0}$ & $\lambda_{1}$ & $\underline{w}$ & $y$ & $N_{0}$ \\
\hline .0043 & .025 & .40 & .12 & 5 & 1.02 & .0509 \\
\hline
\end{tabular}


is an exogenous number $N_{0}$ of potential firms, each with a fixed value of $\theta$ drawn from some exogenous underlying distribution $\Gamma_{0}(\cdot)$. Because for any potential firm productivity is given by $p=y \times \theta$, the only profitable firms in the presence of a wage floor $\underline{w}$ are those with $\theta \geq \underline{w} / y$. The distribution of productivity levels among active firms will thus be given by

$$
\Gamma(p)=\frac{\Gamma_{0}(p / y)-\Gamma_{0}(\underline{w} / y)}{1-\Gamma_{0}(\underline{w} / y)},
$$

and the number of active firms will be $N=N_{0}\left[1-\Gamma_{0}(\underline{w} / y)\right]$. The distribution of potential firm types $\Gamma_{0}(\cdot)$ is then calibrated by shifting the support of the $\Gamma(\cdot)$ distribution obtained as explained in the previous subsection so that its infimum is at $p=1$, and we use that as our benchmark $\Gamma_{0}(\cdot)$ (given the normalization $y=1$ ). We choose the initial contact rate from unemployment $\lambda_{0}$ to generate an initial unemployment rate of $6.4 \%$ and the contact rate from employment $\lambda_{1}$ to match a job-tojob quit rate of $2.78 \%$ with its theoretical counterpart, which is ${ }^{30}$

$$
\frac{\lambda_{1} N}{1-u_{t}} \int_{\underline{p}}^{\bar{p}} \bar{\Phi}(x) L_{t}(x) d \Gamma(x) .
$$

Finally, the number chosen for $N_{0}$ (see table 1) reflects an average firm size of 20 employees.

We model a "boom" as a permanent $2 \%$ increase in $y$ (from $y=1$ to $y=1.02$ ). We further assume that this productivity increase causes the job-finding rate $\lambda_{0}$ to increase by $8 \%{ }^{31}$ and the arrival rate of offers to employed job seekers, $\lambda_{1}$, to increase by $1.6 \%$. If the wage floor $\underline{w}$ does not react, the shock causes entry of $\Delta N=N_{0}\left[\Gamma_{0}(\underline{w})-\Gamma_{0}(\underline{w} / 1.02)\right]$ firms at the bottom of the productivity distribution, all starting off with a size of zero. The distribution of productivity across active firms jumps instantly following (29).

\section{Results}

As can very easily be inferred from equation (8), the response of the unemployment rate to the positive shock hitting the economy is a simple monotonic adjustment toward the new (lower) steady-state value. The interesting feature of that adjustment is its speed: given our calibrated values of $\delta$ and $\lambda_{0}, 90 \%$ of the distance between the initial and the final steady state is covered in less than 6 months.

Figure 14 then shows how employment adjusts at single firms: it shows a plot of $L_{t}(p) / L_{0}(p)$ for four different values of $p$ corresponding 


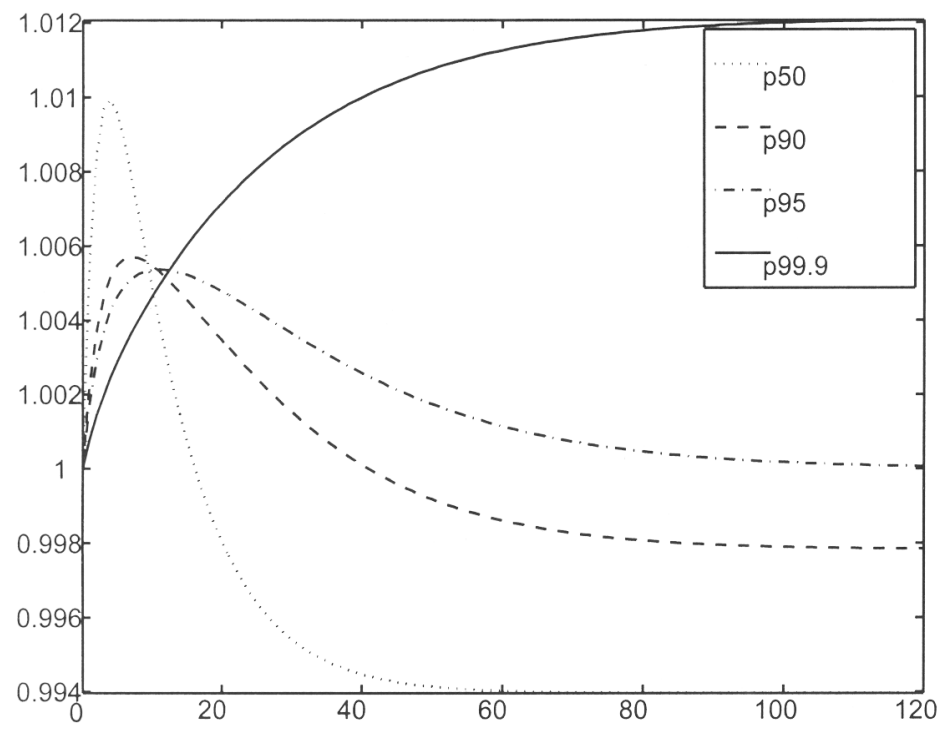

Fig. 14. Firm size dynamics

to the 50th, 90th, 95th, and 99.9th percentiles of the (postshock) distribution of firm types, $\Gamma(\cdot) .^{32}$ Patterns of employment adjustment differ markedly across firm types, which translates into differences across firm size categories since low- $p$ firms are also smaller firms in the initial state of the labor market. One sees in figure 14 that "large" firms tend to increase in size monotonically and gradually (the higher the firm in terms of $p$, the more gradual the adjustment). Conversely, "smaller" firms experience a short episode of rapid growth soon after the shock and then start shrinking back toward their final steady-state size, which they overshoot in the adjustment process. Firms at the 50th percentile of the $\Gamma(\cdot)$ distribution (which places them at the 21st percentile of the sampling distribution $\Phi(\cdot)$ and at the 4.5th percentile in terms of steadystate cumulated employment shares) even end up being smaller after the increase in productivity than in the initial steady state.

This pattern conforms with intuition: in the few months following the shock, most of the new hires are workers coming from unemployment and get disproportionately allocated to small (low- $p$ ) firms, which are the majority in sampling terms. After 6 months or so (given the magnitude of $\lambda_{0}$ ), the unemployment pool dries up and poaching becomes the main channel of hiring. Poaching benefits larger, higher- $p$, better-paying firms at the expense of smaller ones. It occurs later on in the expansion and is a much slower process than the initial siphoning of the unemployment 
pool since $\lambda_{1}$ is about a third of $\lambda_{0}$ in magnitude and the average offer acceptance rate of an employed job seeker is less than one.

For comparison with the descriptive evidence shown in Section II, the mechanism just described can be depicted in terms of employment shares and average growth rates by firm size category. This is done in figures 15, 16, and 17, which parallel figures 2-4 from Section II.

The response of the average job-to-job quit rate is plotted in figure 18 . Apart from the initial jump caused by the assumed instant response of $\lambda_{1}$ to the productivity shock, the average quit rate has an initial increasing phase that reflects the initial disproportionate inflow of new hires into small, low-productivity firms. These workers start getting poached away by larger firms relatively easily, while at the same time the unemployment pool quickly gets depleted and the excess inflow of workers into easy-topoach positions slows down. As workers gradually get reallocated toward more productive, better-paying firms, poaching becomes more difficult (the acceptance rate of outside offers falls) and the quit rate falls.

Finally, figures 19, 20, and 21 plot the dynamic responses of mean wages, mean output per worker, and the mean labor share, respectively. The path followed by mean output per worker results from a pure composition effect. After the initial upward jump caused by the sudden $2 \%$ increase in the productivity levels of all established firms, mean output

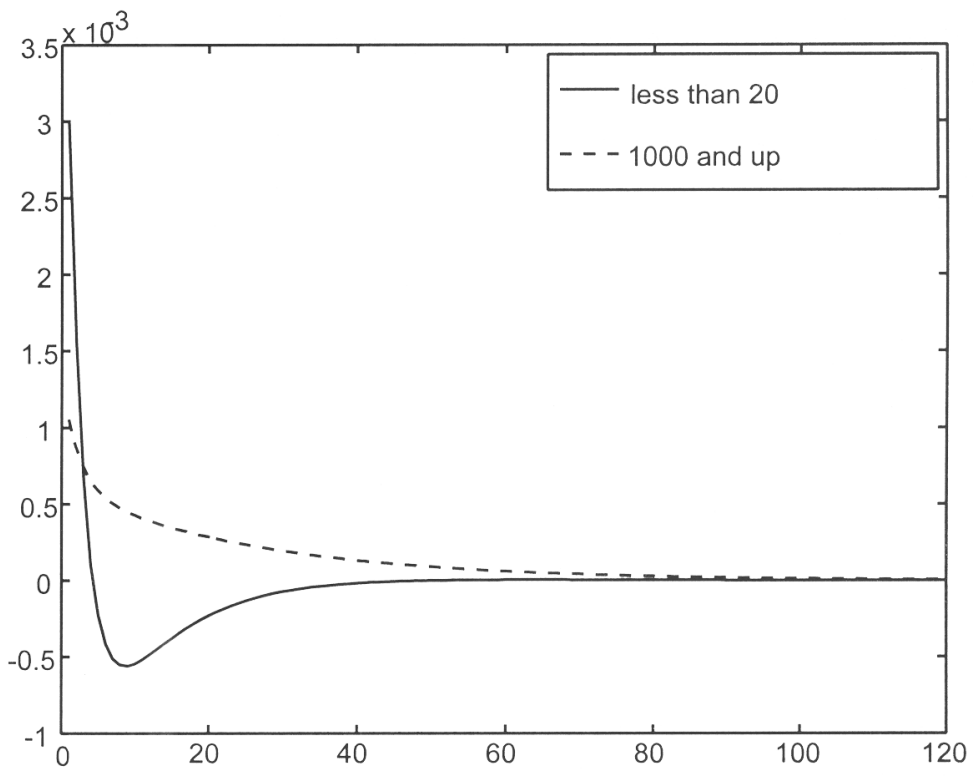

Fig. 15. Firm growth, small vs. large firms 


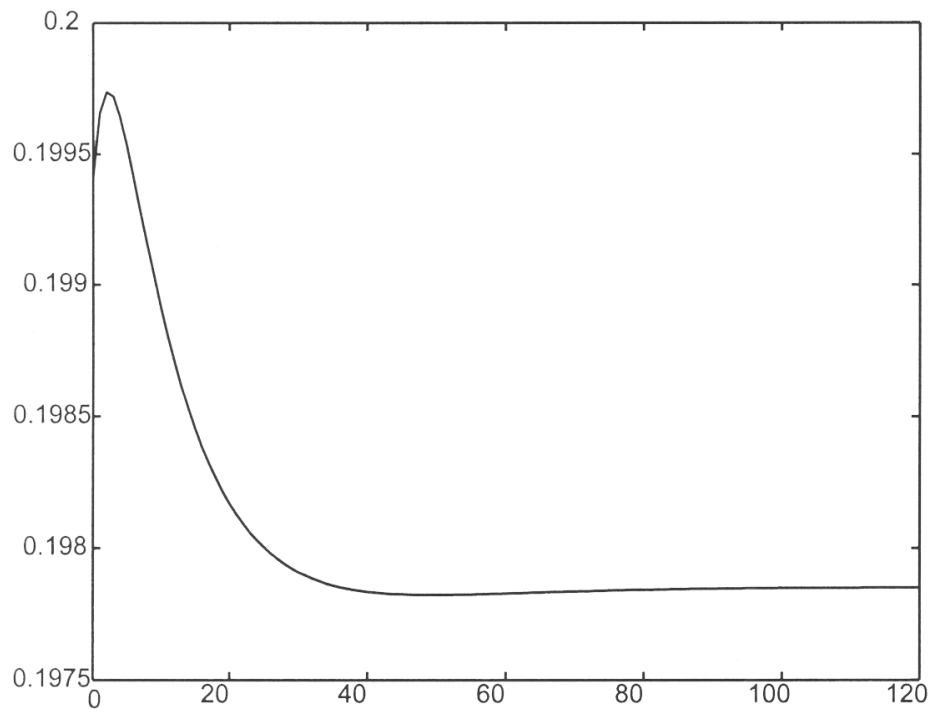

Fig. 16. Employment shares (firms < 20)

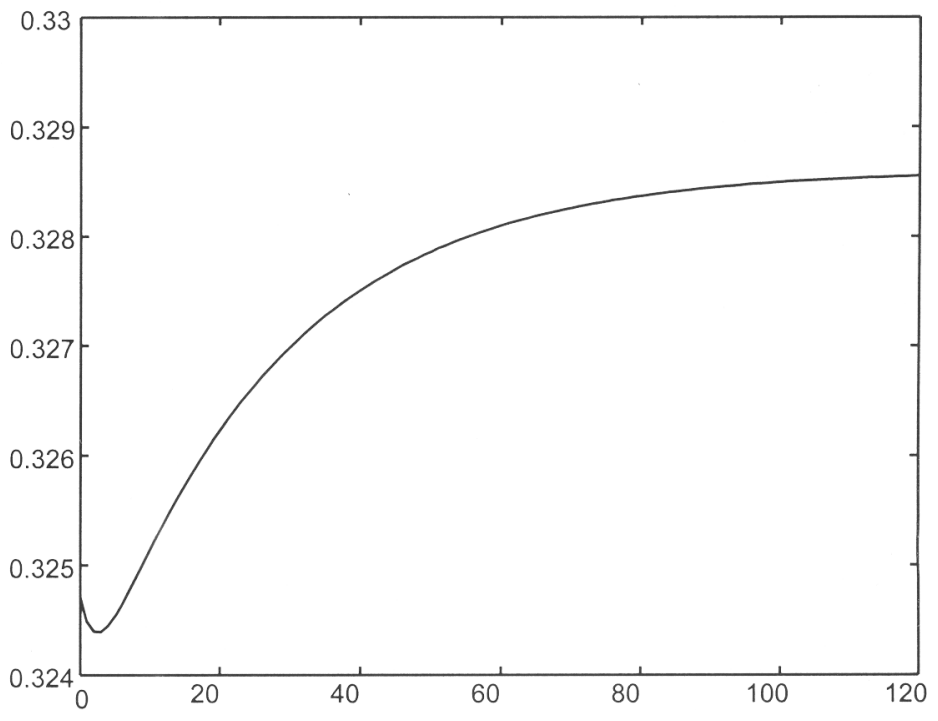

Fig. 17. Employment shares (firms $\geq 1,000$ ) 


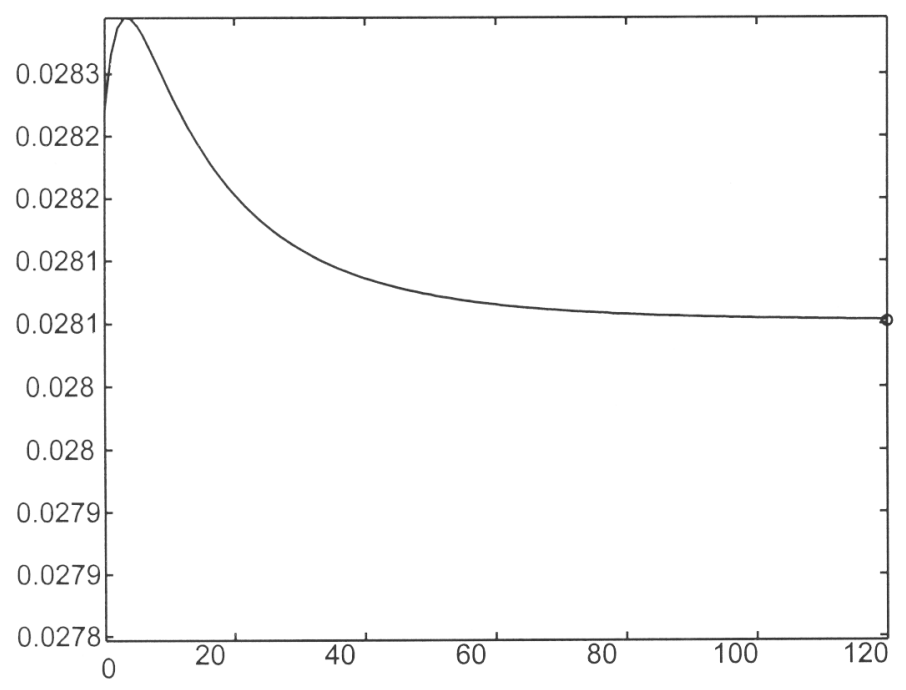

Fig. 18. Average job-to-job quit rate

per worker adjusts quasi-monotonically to its higher final steady-state value following the gradual reallocation of newly hired workers into more productive firms. The slight dip observed in the initial phase of that adjustment is due to the mass of low-productivity firms suddenly becoming viable as a result of the positive aggregate shock on $y$ and

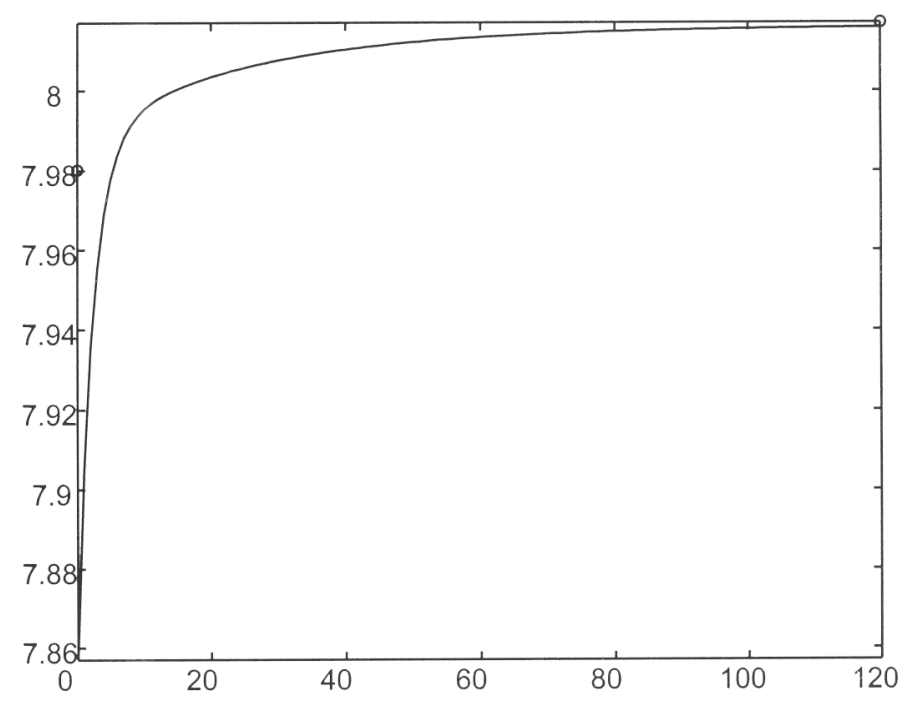

Fig. 19. Mean wage 


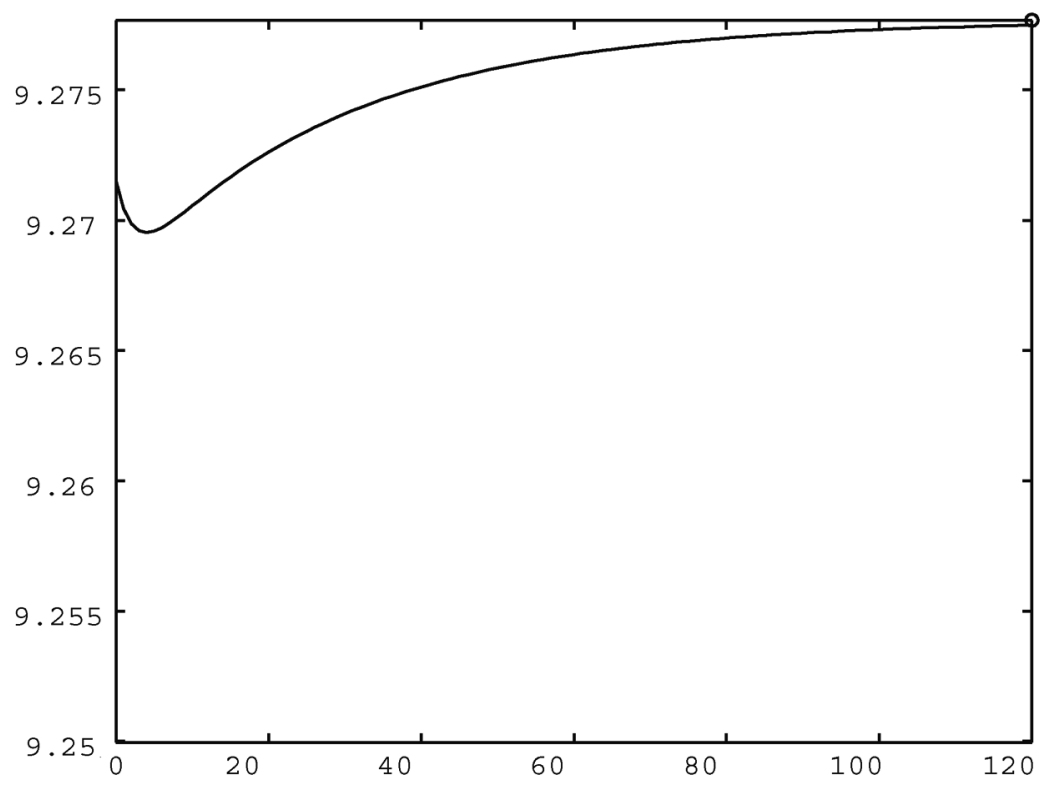

Fig. 20. Mean output per worker

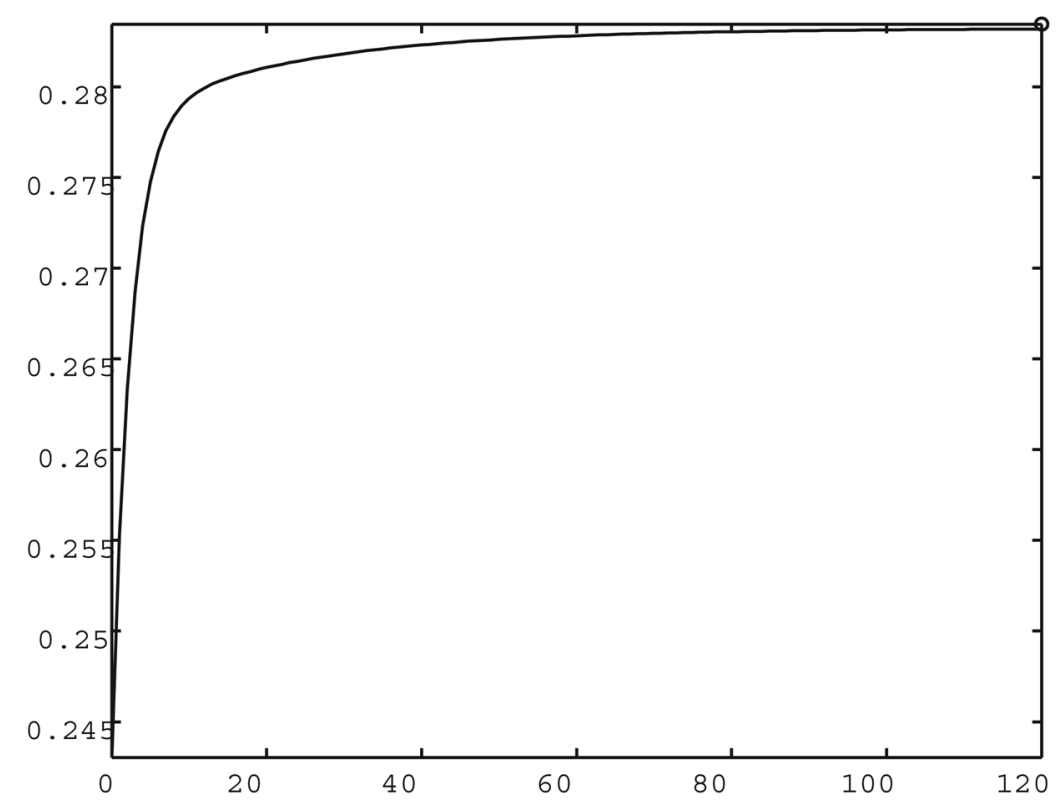

Fig. 21. Mean labor share 
thus entering the market with an initial size of zero. These entrant firms drag average output per worker down in the early phase of the expansion as they hire some workers into low-productivity jobs.

The mechanisms generating the path followed by the mean wage are more intricate. First, the same composition effect as for mean output per worker operates for wages: there is an initial excess inflow of workers into low-paying firms, and those workers gradually reallocate themselves into better-paying firms, thereby causing a sluggish positive response of the mean wage to the aggregate productivity shock. Note that, because of this composition effect, the aggregate mean wage would exhibit this sluggish adjustment pattern even if all firm-level wages would jump right onto their new steady-state values upon impact of the productivity shock. ${ }^{33}$ Second, each firm-level wage follows a dynamic path of its own. Wages are back-loaded to the late part of the expansion. The composition of these individual dynamic paths causes the initial downward jump in the mean wage: the effect on the intensive margin, the withinfirm back-loading, dominates the aggregate wage at first.

Combining the output and wage series, one can visualize the dynamic response of the labor share (fig. 21). This is an interesting plot to look at, in light of a recent paper by Choi and Ríos-Rull (2008), who show that the labor share is countercyclical and persistent. Our model replicates these facts, in that figure 21 resembles the impulse response function produced by their vector autoregression analysis: the labor share decreases on impact of a positive aggregate shock and then gradually increases back toward its new steady-state value. This, however, is only a half success, since our model also fails on two important points. First, Choi and Ríos-Rull also identify an overshooting property of the labor share: the labor share impulse response function peaks after 5 years at a higher level than the initial and final steady states. ${ }^{34}$ Although the initial dip in average output per worker (see fig. 20) would in principle help generate this overshooting of the labor share in our model, it does not seem to be enough. ${ }^{35}$ Second, our model predicts a labor share of $25 \%-30 \%$, which is about half the number observed in the data. This is related to a fundamental problem of the Burdett-Mortensen model, which can replicate only an empirically sensible wage density given a distribution of firm productivity with a very long right tail, resulting in profit rates close to $100 \%$ for a substantial fraction of highly productive firms (see, e.g., Postel-Vinay and Robin [2006] for a discussion of this problem). Modeling explicitly capital and recruiting costs would certainly reduce profits and raise the labor share toward plausible values in the calibrated model. 
Our quantitative example features a strong propagation in wages, labor productivity, and the labor share, which keep rising years after the initial shocks, although the unemployment rate's half-life is just a few months. The main reason is that job-to-job transitions in the data are an order of magnitude slower than the reallocation from unemployment to employment. Thus, the upgrading process is slow, and so is the rise in labor productivity after an initial jump following the shock. The propagation is less pronounced for the EE rate. We are ignoring further sources of propagation of the unemployment rate, such as endogenous labor force participation. This is likely to rise in the expansion, feeding the market with relatively cheap candidates for hiring from unemployment and delaying the moment when large firms have to start raising wages aggressively to poach workers, the small firms have to respond to retain them, and the EE rate peaks. However, our figure 1 shows that participation seems to play a very minor role at business cycle frequencies. Finally, our quantitative exercise does not feature a strong amplification of aggregate productivity shocks on unemployment, a subject of much debate in recent years (Shimer 2005). This is not our main focus, and at any rate the present exercise is just one initial attempt to gain traction on the new evidence that we present.

\section{Discussion: The Sources of Wage Back-Loading}

When workers can quit to other employers, it is always in a firm's interest to back-load wage payments. In this version of the Burdett-Mortensen model, because firms must pay all workers the same, they are not allowed to index wages to individual tenure and to back-load individual wages-as they would do in the wage-tenure models of Burdett and Coles (2003) and Stevens (2004). However, firms can index contracts to calendar time and benefit from future competition from higher-paying firms. Specifically, the prospect of receiving an offer from a better-paying firm later on makes up for the low wage that a single firm offers today. In other words, superior firms impose a "top-down" externality on inferior firms through future poaching, which encourages the latter to back-load wages. Promising high future wages is advantageous because, with some chance, they will be delivered by stronger competitors. Furthermore, a superior firm's response to an inferior firm's back-loading is to back-load itself by offering slightly more at all dates-just enough to maintain its rank and poach workers away from the lower- $p$ firm, a reinforcing "bottom-up" strategic complementarity. Note that, unlike the former top-down externality, the bottom-up mechanism has no time dimension per se. 
Aggregate dynamics introduce an independent motive for back-loading wages. When unemployment declines and the resulting inflow of cheap workers into firms with it, firm growth slows down. At that point, more productive firms, which have more to lose from not employing workers, find it profitable to raise wages to raid smaller, less productive competitors. The latter, in turn, respond by raising wages to retain their workers. This direct impact of unemployment on the level of wages gives rise to a back-loading in calendar time that originates purely from the time-varying scarcity of cheap job applicants.

Another difference from the wage-tenure models cited above is that our contract-posting model delivers smooth back-loading despite risk neutrality, whereas Stevens (2004) shows that the optimal (back-loaded) wage-tenure contract offered to risk-neutral workers is a step contract (Burdett and Coles [2003] show how worker risk aversion entails gradual back-loading). In our case, the gradual nature of back-loading is purely driven by strategic considerations.

The extent to which firms can piggyback on their future competitors depends on the workers' (relative to the firms') horizon. Most of the analysis so far was based on the assumption that workers and firms were equally patient and shared a finite discount rate $\rho=r$. As argued in Section IV, however, the model is well defined with different discount rates for firms and workers, in which case an additional motive for back-loading comes into play: intertemporal trading. Intuitively, the more patient the worker relative to the firm, the more back-loading we should expect. We address this issue formally in Moscarini and Postel-Vinay (2008).

\section{Conclusion}

We document three new facts about aggregate dynamics in U.S. labor markets over the last two decades, drawing in part from newly available data sets. We discover a strong comovement between the share of employment at large firms, the employer-to-employer worker transition rate, and various measures of wages. All three remain below trend several years into the expansion. Then, simultaneously, employment shifts toward large firms, workers start quitting more from job to job, and wages accelerate.

While the period under consideration, owing to data availability, is too short to establish any new stylized facts about business cycles, this evidence suggests a new view of how labor markets function, or at least functioned in the last two cycles. More productive firms pay higher 
wages and thus hire, employ, and retain more workers. Early in an expansion, when unemployed job applicants are plentiful, all firms exploit their monopsony power and pay low wages. As few workers are employed, in particular at small firms, the aggregate job-to-job quit rate is small. As the pool of unemployment dries out, small firms find it increasingly difficult to keep hiring, whereas large firms can now poach from small firms their larger employment pool. So the aggregate quit rate rises and the share of employment at large firms increases. Aggregate wages rise for two reasons. First, workers climb to higher-paying firms, so there is a composition effect. Second, firms offer wage profiles that increase over time. The increased competition for employed workers erodes firms' monopsony power and leads to a redistribution of rents from profits to salaries late in an expansion.

We investigate whether this view is consistent with the transitional dynamics of the Burdett and Mortensen (1998) equilibrium search model, analyzed in a companion paper (Moscarini and Postel-Vinay 2008). In our model, following a positive aggregate shock to labor demand, wages respond little on impact and start rising only when firms run out of cheap unemployed hires and start competing to poach and to retain employed workers. Aggregate shocks are thus propagated by the hiring behavior of large firms. A calibrated example shows that the model qualitatively captures the essence of the three facts.

Our analysis presents several limitations. On the empirical side, as firm productivity is not easily observable, we proxy it by firm size, as suggested by the model. Firm size is, however, endogenous and evolving over time. Thus, to conclusively establish that the employment share of small firms peaks at cyclical troughs, we need a panel of employers to identify those that are small at the end of the recession. So far, we have made use of publicly available longitudinal information on firms and establishments. Much work remains to be done to add micro detail and to extend the analysis back in time, using existing but confidential resources.

On the theoretical side, in order to focus on the role of aggregate dynamics in the contract-posting game, we abstract from the possibility that such contracts may be conditioned on worker tenure, employment status of the applicant, or other features. Also we adopted a rather minimal description of the search technology (exogenous and constant worker-firm contact rates), mainly in order to maintain tractability. Next, the thought experiment is the adjustment to a one-shot aggregate shock. But ideally we would like to characterize dynamics in an explicitly stochastic model, with aggregate uncertainty recognized by all agents, including downturns that we have so far ignored in the analysis. Finally, we are aiming to obtain a full analytical characterization of the dynamic equilibrium. 
On the quantitative side, our results still present a large margin of improvement. The half-life of the main time series of interest produced by the simulation is an order of magnitude shorter than in the data. We expect that introducing partially persistent aggregate shocks and/or relaxing some of the theoretical restrictions listed above will fill much of this gap. We place exclusive focus on one friction, job search, as the common source of the firm's boundaries and size, wage dynamics, and worker flows. It is natural to think about additional frictions that affect firm size and that operate differentially at different levels of size, such as borrowing constraints.

\section{Appendix}

\section{A Numerical Equilibrium Determination}

The algorithm we use to numerically characterize the dynamic equilibrium is based on the restriction that, if the minimum wage constraint binds for some firms, it will do so at early stages of the expansion only. In other words, any firm can choose to post the minimum wage for a while right after the productivity shock, but once it ceases to do so, it is not allowed to return to the minimum wage. Simulations will prove that an equilibrium with exactly this pattern exists.

In order to construct that equilibrium, we proceed through the following steps.

Step 1. Consider some productivity level $p_{0}$ such that the functions $\pi_{t}\left(p_{0}\right)$ and $\mu_{t}^{\prime}\left(p_{0}\right)$ are known. (In effect the algorithm is started at $p_{0}=$ $\underline{p}$ for which those functions are known from [25].) Pick a step size $h$.

Step 2. Construct a candidate $\pi_{t}\left(p_{0}+h\right)$ using the second (static) differential equation in (23), such as ${ }^{36}$

$\tilde{\pi}_{t}\left(p_{0}+h\right)=\pi_{t}\left(p_{0}\right)+h \times\left[\mu_{t}^{\prime}\left(p_{0}\right)-\frac{2 \lambda_{1} \gamma\left(p_{0}\right) L_{t}\left(p_{0}\right)}{\left(\lambda_{0} u_{t} / N\right)+\lambda_{1} \int_{\underline{p}}^{p_{0}} L_{t}(x) d \Gamma(x)} \pi_{t}\left(p_{0}\right)\right]$.

Step 3. Construct a candidate wage path for type $\left(p_{0}+h\right)$ firms from $\tilde{\pi}_{t}\left(p_{0}+h\right)$ and equation (12):

$$
\widetilde{w}_{t}\left(p_{0}+h\right)=p_{0}+h-\left[r+\delta+\lambda_{1} \bar{\Phi}\left(p_{0}+h\right)\right] \tilde{\pi}_{t}\left(p_{0}+h\right)+\dot{\tilde{\pi}}_{t}\left(p_{0}+h\right) .
$$


Step 4. Construct $w_{t}\left(p_{0}+h\right)$ and $\pi_{t}\left(p_{0}+h\right)$ as follows:

- If $\tilde{w}_{t}\left(p_{0}+h\right) \geq \underline{w}$ at all dates, set $w_{t}\left(p_{0}+h\right)=\widetilde{w}_{t}\left(p_{0}+h\right)$ and $\pi_{t}\left(p_{0}+\right.$ $h)=\tilde{\pi}_{t}\left(p_{0}+h\right)$ for all $t$.

- If $\tilde{w}_{t}\left(p_{0}+h\right)<\underline{w}$ for $t \in\left[0, t^{*}\right]$, set $w_{t}\left(p_{0}+h\right)=\tilde{w}_{t}\left(p_{0}+h\right)$ and $\pi_{t}\left(p_{0}+\right.$ $h)=\tilde{\pi}_{t}\left(p_{0}+h\right)$ for all $t>t^{*}$ and set $w_{t}\left(p_{0}+h\right)=\underline{w}$ and

$$
\begin{aligned}
\pi_{t}\left(p_{0}+h\right)= & \tilde{\pi}_{t^{*}}\left(p_{0}+h\right) e^{-\left[r+\delta+\lambda_{1} \bar{\Phi}(p)\right]\left(t^{*}-t\right)} \\
& +\frac{p_{0}+h-\underline{w}}{r+\delta+\lambda_{1} \bar{\Phi}\left(p_{0}+h\right)}\left\{1-e^{-\left[r+\delta+\lambda_{1} \Phi\left(p_{0}+h\right)\right]\left(t^{*}-t\right)}\right\}
\end{aligned}
$$

for $t \in\left[0, t^{*}\right]$. (Note that $t^{*}$ may depend on $p_{0}$.)

Step 5. Use $w_{t}\left(p_{0}+h\right)$ and $\pi_{t}\left(p_{0}+h\right)$ constructed at step 4 to solve for $\mu_{t}^{\prime}\left(p_{0}+h\right)$ in the first equation of (23):

$$
\begin{aligned}
\mu_{t}^{\prime}\left(p_{0}+h\right)= & \int_{t}^{+\infty}\left[1+\lambda_{1} \gamma\left(p_{0}+h\right) q\left(p_{0}+h\right) \pi_{t}\left(p_{0}\right.\right. \\
& +h)] e^{-\left[r+\delta+\lambda_{1} \Phi\left(p_{0}+h\right)\right](s-t)} d s
\end{aligned}
$$

Step 6. Start over at step 1 substituting $p_{0}+h$ for $p_{0}$.

\section{Endnotes}

We would like to thank Robert Hall and Robert Shimer for their discussions of and suggestions on this article; Daron Acemoglu, David Berger, Pat Kline, and Gianluca Violante for helpful conversations on this project; David Talan and Charles Carson from the Bureau of Labor Statistics for providing unpublished data on the firm size distribution in the BED data set; Bige Kahraman and Rafael Melo for excellent research assistance; and seminar audiences at Boston University, Bristol, Carlos III, Edinburgh, Essex, Calgary, the Federal Reserve Bank of Chicago, New York University, Penn State, Princeton, Southampton, Toronto, University College London, Wurzburg, Yale, and conference participants from the 2007 NBER Summer Institute, the 2008 Association for the Development of Research in Economics and Statistics/EDHEC conference on Labor Market Outcomes: A Transatlantic Perspective, the 2008 Malaga conference on advances in the analysis of labor markets with frictions, and the 2008 NBER Macroeconomics Annual for very useful feedback. PostelVinay gratefully acknowledges financial support from the Economic and Social Research Council (grant reference RES-063-27-0090). The usual disclaimer applies.

1. To our knowledge, Shimer (2003) is the only prior attempt to analyze aggregate dynamics in a wage-posting search model. See $\mathrm{n}$. 20 below for a brief description and Robert Shimer's discussion of this article in this same volume.

2. Shimer's unconventional value of $10^{5}$ has been criticized as smoothing too much. We also tried a more conventional quarterly parameter of 1,600 , transformed into a monthly frequency by multiplying it by $3^{n}$ for $n=2,3$, or 4 . The resulting trends cross well above and below the actual values repeatedly through NBER-dated expansions, suggesting that low-frequency demographic changes are contaminating (un)employment fluctuations. 
3. A moving average (MA) smoother was further applied to the HP-filtered series. All infrayearly (i.e., monthly or quarterly) series plotted in this section are MA smoothed for legibility.

4. Considering standard cutoff sizes to define "small" vs. "large" businesses, we can use data from the County Business Pattern files (see below for a presentation of this data set) to compare establishments with a workforce in excess of 500 employees with establishments in the category 1-19 employees. The latter create more jobs (or destroy fewer) around recession years, i.e., 1989-90, 1990-91, less so in 1991-92, and again in 2001-2. In all other years, 1992-2000 and 2002-4, large establishments create more jobs in total. Details are available on request. On this subject, see also Neumark, Wall, and Zhang (2008).

5. For more information and to download the data, visit http://www.bls.gov/bdm/. David Talan and Charles Carson from the BLS kindly tabulated for us the firm size distribution for all available quarters.

6. Visit http://www.census.gov/csd/susb/susb.htm and http://www.sba.gov/ advo/research/data.html for more information and data files.

7. These cyclical patterns do not appear to be specific to U.S. firms or establishments. Although we have not found our new facts spelled out anywhere, disparate pieces of evidence now fall into place. Delli Gatti et al. (2004) find in a very large sample of Italian firms that the distribution of employment size becomes less concentrated on large firms in the aftermath of the 1992 recession and then regains concentration over the ensuing expansion. This fact is consistent with small firms accounting for a larger share of employment early in an expansion, since this corresponds to a drop in concentration. Data from the U.K. Labor Force Survey that we have elaborated (not reported, available on request) convey information about the share of workers whose workplace has fewer than 25 employees. Also the U.K. Small Business Administration publishes data on the shares of U.K. employment in firms with fewer than 20 and more than 249 employees. Both sources suggest that small U.K. firms lost employment to large ones in expansions, with sudden reversals in the 1991 and 2002 aggregate slumps, just as in the United States. On the sensitivity of large employers to recessions, Broersma and Gautier (1997) find in a panel of Dutch manufacturing firms that large ones restructure their employment mostly in recessions, whereas small firms do it all the time independently of the cycle. Finally, Caballero, Engel, and Micco (2004) find in four Latin American countries that large manufacturing plants adjust much more rapidly to shocks, including aggregate ones, than small plants.

8. On both bottom panels the straight line materializes a linear trend and the shaded area shows the $95 \%$ confidence band around that trend.

9. All are deviations from trend. The trend used for the unemployment rate is the HPfiltered series mentioned above, and the trend used for the (much shorter) series of growth rate differentials is just a linear trend. Note that a very similar-looking graph obtains when one uses the E/POP ratio instead of the unemployment rate as an indicator of labor market tightness.

10. Interestingly, it would seem that the growth rate difference is a leading indicator of the unemployment rate. The correlation between unemployment and the growth rate difference lagged one quarter is about -0.82 .

11. Visit http://www.census.gov/csd/susb/susb.htm for more information and data files.

12. Details of how we have mapped Standard Industrial Classification and (subsequently) North American Industry Classification codes into these eight industries are available on request.

13. In the NBER Manufacturing Panel from Compustat, with firm sizes fixed in 1975, the difference in growth rates of employment between firms in the top quartile and firms below the median has the now familiar pattern throughout 1975-95: falling in recessions and gradually climbing in expansions. This is true whether we define size in terms of 
initial employment, sales, capital, or assets. We thank David Berger for these calculations. Results are available on request.

14. The critical change in CPS interviewing procedures, which made measurement of the EE transition rate possible, is the introduction of dependent coding of industries and occupations. Before asking specific questions about those, starting in 1994 CPS interviewers first read to the survey respondent his or her answers from the previous month and asked whether anything, including the worker's employer, had changed. The resulting EE transition rate cannot detect unemployment spells that last less than 3 weeks. So, strictly speaking, it is not a job-to-job quit rate. The definition of such a quit rate is, however, to some extent subjective. The worker may take a voluntary break before starting a previously lined up new job. Furthermore, Moscarini and Thomsson (2007) also control for job search activity in the intervening month and find little difference.

15. Information about the SIPP and data files are available at http:/ / www.census.gov / $\operatorname{sipp} /$.

16. Specifically, it is constructed as the fraction of workers who have changed employers in the previous year and are now employed at an establishment in size category $X$ without work interruption among all workers having changed employers in the previous year and now employed at an establishment in size category $X$.

17. Although some of the size-wage gap is explained by workforce composition (which is obviously ignored in fig. 13), the voluminous literature on this matter establishes that significant firm size-wage effects remain after one controls for various worker and job characteristics. Those results are discussed in great detail in Oi and Idson (1999).

18. Sharpe (1994) replicates Gertler and Gilchrist's findings for employment growth by initial size defined in terms of net capital. He uses the NBER Manufacturing Panel from Compustat. As mentioned earlier, in the same data set, now extended by a few years, our pattern of differential growth rate by initial size still emerges at NBER-dated business cycles.

19. The following excerpts from CNNMoney.com reports relate to the perceived 2007-8 turning point in the U.S. labor market: "Job seekers now are in the driver's seat,' the Chicago-based outplacement firm Challenger Gray \& Christmas observes. 'Low unemployment throughout last year forced companies to increase wages and offer new perks in order to attract and retain the most talented people'" (March 28, 2007). And a year later, precursory signs of a looming recession are posted by commercial forecasters: "Another sign from workers that the labor market is getting difficult: There has been a sharp decline in the number of workers willing to quit their jobs. ... 'When the quit rate is low, it's a very bad sign,' said economist Robert Bruca of FAO Economics" (March 6, 2008). "Joel Prakken, chairman of Macroeconomic Advisors, which processes the ADP payroll services data to produce the report, says what is notable is the decline in employment among medium size employers, those with 50 to 499 employees" (March 6, 2008).

20. As mentioned in the introduction, Shimer (2003) is the only prior attempt that we know of to analyze the out-of-steady-state behavior of a search/wage-posting model. He considers a dynamic extension of the Burdett-Mortensen model in which homogeneous firms can commit to only constant wage profiles also out of steady state, but the firm must not pay the same wage to all its workers. Because our analysis is motivated as much by the new evidence that we present as by the model per se, we assume that heterogeneous firms post time-dependent wage contracts.

21. There are various ways to endogenize an increasing sampling density. If each firm faces a convex cost of posting vacancies, in equilibrium more productive firms will post more vacancies since they are more profitable, so they will be sampled more often. This extension also allows one to endogenize the contact rates $\lambda_{0}$ and $\lambda_{1}$. Alternatively, the greater visibility of more productive, larger firms attracts more unsolicited job applications. For example, news of job vacancies may travel by word of mouth; the more employees work for the same employer, the more of their friends will hear of its open 
positions. Finally, if search has any element of directness, equilibrium mandates that people apply more to high-paying, productive firms to trade off the level of the wage offer against the chance of getting it.

22. Or, less stringently, we allow firms to index wages to any aggregate variable that evolves monotonically over time (e.g., the unemployment rate). We thus rule out, among other things, wage-tenure contracts (Burdett and Coles 2003; Stevens 2004), offer matching or individual bargaining (Postel-Vinay and Robin 2002; Dey and Flinn 2005; Cahuc, Postel-Vinay, and Robin 2006), or contracts conditioned on employment status (CarrilloTudela 2007). Note, however, that the model can be generalized to allow for time-varying individual heterogeneity under the assumption that firms offer the type of piece rate contracts described in Barlevy (2008). In that sense experience and/or tenure effects can be introduced into the model. As Robert Shimer clarifies in his discussion of this paper, our proposed solution to the firm's problem will also implicitly assume that firms can charge an initial lump sum to workers at date 0 . We refer the reader to Shimer's discussion for more on this subtle yet important issue and take this opportunity to thank him for clarifying this point.

23. Incidentally, this implies that the probability density of firm types among workers at date $t$ is given by $N L_{t}(p) \gamma(p) /\left(1-u_{t}\right)$.

24. In formulating (1), we assume for simplicity that any job offer posted in equilibrium is preferred to unemployment, i.e., $\inf _{p} V_{t}(p) \geq U_{t}$ at all $t$. This is achieved by assuming that the minimum wage $\underline{w}$ is sufficiently higher than $b$ for unemployed workers to find even the least valuable job offer worth accepting.

25. As argued in Moscarini (2005), not responding to outside offers is a sequential equilibrium of an ascending (English) auction between the incumbent and the poacher and the unique equilibrium that survives natural refinements. The more productive of the two firms wins without offering more than it does to its other workers because it can always respond to any attempt by the competitor to outbid it, even if the competitor trembles. In this case, our assumption of no ex post competition is not particularly restrictive. If the auction is instead simultaneous with either one bid or a sealed bid, as in Bertrand (Postel-Vinay and Robin 2002), then firms would bid their maximum valuation and our assumption has bite.

26. We thank Pat Kline for pointing this out to us.

27. Note that the following law of motion can also by obtained by integration of (3) with respect to $p$. Details are available on request.

28. To see this, notice that (12) and (19) yield two different growth rates for $\pi_{t}(p)$ if all wages are constant and the economy is off its steady state (so that firm sizes change over time). Equation (12) gives a $\pi_{t}(p)$ that evolves as an exponential of time. But then with a constant wage and constant wages offered elsewhere, $V_{t}^{\prime}(p)$ is constant over time. So dividing (19) by $L_{t}(p)$ tells us that $\pi_{t}(p)$ is proportional to the gross hiring rate, and so $\pi_{t}(p)$ cannot be exponential in time (because the hiring rate is not an exponential function of time in an RPE). All this implies that posting a constant wage in the face of competitors themselves posting constant wages violates the firm's set of necessary optimality conditions.

29. Although the model is silent about the firm/establishment distinction and our evidence is equally valid for either definition, we have to make a choice at this point of the calibration procedure. In the spirit of Burdett and Mortensen, we envision a firm as a wage policy.

30. The acceptance rate of outside offers becomes

$$
\frac{\delta}{\lambda_{1}}\left[\left(1+\frac{\delta}{\lambda_{1}}\right) \ln \left(1+\frac{\lambda_{1}}{\delta}\right)-1\right]
$$

at a steady state, i.e., about 0.23 with our parameterization.

31. This is based on an elasticity of labor market tightness with respect to productivity of 8 and an elasticity of the job-finding rate with respect to labor market tightness of 0.5 , both consensual numbers. 
32. The normalization by $1 / L_{0}(p)$ is just there to rescale the paths and keep the picture legible. Moreover, on all figures, circles on the axes indicate initial (steady-state) values of the various indicators plotted.

33. This is precisely the situation that would arise under the special assumption of infinitely impatient workers (workers with an infinite rate of future discount). The full details of that special case are in Moscarini and Postel-Vinay (2008).

34. Incidentally, the final steady-state labor share is slightly higher than the initial one in our calibration exercise. This results from the comparative static properties of the BurdettMortensen model.

35. This could potentially be fixed by "prolonging" the dip in output per worker, which could be achieved by assuming that the initial entry of low-productivity firms is only gradual.

36. The following uses a simple Euler approximation. In practice we use a two-step Runge-Kutta approximation for numerical accuracy.

\section{References}

Barlevy, G. 2001. "Why Are the Wages of Job Changers So Procyclical?" Journal of Labor Economics 19, no. 4:837-78.

$\rightarrow$. 2008. "Identification of Search Models Using Record Statistics." Review of Economic Studies 75, no. 1:29-64.

$\rightarrow$ Beaudry, P., and J. DiNardo. 1991. "The Effect of Implicit Contracts on the Movement of Wages over the Business Cycle: Evidence from Micro Data." Journal of Political Economy 99, no. 4:665-88.

$\rightarrow$ Bils, M. 1985. "Real Wages over the Business Cycle: Evidence from Panel Data." Journal of Political Economy 93 (August): 666-89.

$\rightarrow$ Bils, M., and K. McLaughlin. 2001. "Inter-industry Mobility and the Cyclical Upgrading of Labor." Journal of Labor Economics 19, no. 1:94-135.

$\rightarrow$ Bontemps, C., J.-M. Robin, and G. J. Van den Berg. 2000. "Equilibrium Search with Continuous Productivity Dispersion: Theory and Non-parametric Estimation." International Economic Revieww 41, no. 2:305-58.

$\rightarrow$ Broersma, L., and P. Gautier. 1997. "Job Creation and Job Destruction by Small Firms: An Empirical Investigation for the Dutch Manufacturing Sector." Small Business Economics 9, no. 3:211-24.

$\rightarrow$ Burdett, K., and M. Coles. 2003. "Equilibrium Wage-Tenure Contracts." Econometrica 71 , no. 5:1377-1404.

$\rightarrow$ Burdett, K., and D. T. Mortensen. 1998. "Wage Differentials, Employer Size and Unemployment." International Economic Review 39:257-73.

Caballero, R., E. Engel, and A. Micco. 2004. "Microeconomic Flexibility in Latin America." Working Paper no. 10398, NBER, Cambridge, MA.

$\rightarrow$ Cahuc, P., F. Postel-Vinay, and J.-M. Robin. 2006. "Wage Bargaining with On-theJob Search: Theory and Evidence." Econometrica 74, no. 2:323-64.

Carrillo-Tudela, C. 2007. "Offers Conditioned on Employment Status: An Equilibrium Search Approach." Manuscript, University of Leicester.

Choi, S.-K., and J.-V. Ríos-Rull. 2008. "The Labor Share: Disciplining Device for RBC Models?" Manuscript, University of Minnesota.

$\rightarrow$ Cooley, T. F., and V. Quadrini. 2001. "Financial Markets and Firm Dynamics." American Economic Review 91, no. 5:1286-1310.

Delli Gatti, D., C. Di Guilmi, E. Gaffeo, G. Giulioni, M. Gallegati, and A. Palestrini. 2004. "Business Cycle Fluctuations and Firms' Size Distribution Dynamics." Advances in Complex Systems 7, no. 2:1-18.

$\rightarrow$ Dey, M. S., and C. J. Flinn. 2005. "An Equilibrium Model of Health Insurance Provision and Wage Determination." Econometrica 73, no. 2:571-627. 
$\rightarrow$ Diamond, P. 1971. "A Model of Price Adjustment." Journal of Economic Theory 3:156-68.

$\rightarrow$ Gertler, M., and S. Gilchrist. 1994. "Monetary Policy, Business Cycles, and the Behavior of Small Manufacturing Firms." Quarterly Journal of Economics 109, no. 2:309-40.

$\rightarrow$ Moscarini, G. 2005. "Job Matching and the Wage Distribution." Econometrica 73, no. 2:481-516.

Moscarini, G., and F. Postel-Vinay. 2008. "Non-stationary Search Equilibrium." Manuscript, Yale University and University of Bristol.

$\rightarrow$ Moscarini, G., and K. Thomsson. 2007. "Occupational and Job Mobility in the US." Scandinavian Journal of Economics 109, no. 4:807-36.

Neumark, D., B. Wall, and J. Zhang. 2008. "Do Small Businesses Create More Jobs? New Evidence from the National Establishment Time Series." Working Paper no. 13818, NBER, Cambridge, MA.

Oi, W., and T. L. Idson. 1999. "Firm Size and Wages." In Handbook of Labor Economics, ed. O. Ashenfelter and D. Card. Amsterdam: Elsevier Science.

$\rightarrow$ Okun, A. 1973. "Upward Mobility in a High Pressure Economy." Brooking Papers on Economic Activity, no. 1:207-52.

$\rightarrow$ Postel-Vinay, F., and J.-M. Robin. 2002. "Equilibrium Wage Dispersion with Worker and Employer Heterogeneity." Econometrica 70, no. 6:2295-2350.

- 2006. "Microeconometric Search-Matching Models and Matched EmployerEmployee Data." In Advances in Economics and Econometrics, Theory and Applications: Ninth World Congress, ed. R. Blundell, W. Newey, and T. Persson. Cambridge: Cambridge University Press.

$\rightarrow$ Romer, C., and D. Romer. 1989. “Does Monetary Policy Matter? A New Test in the Spirit of Friedman and Schwartz." NBER Macroeconomics Annual 4:121-70.

$\rightarrow$ Rossi-Hansberg, E., and M. L. J. Wright. 2007. "Establishment Size Dynamics in the Aggregate Economy." American Economic Review 97, no. 5:1639-66.

$\rightarrow$ Sharpe, S. 1994. "Financial Market Imperfections, Firm Leverage, and the Cyclicality of Employment." American Economic Review 84, no. 4:1060-74.

Shimer, R. 2003. "Out-of-Steady-State Behavior of the Burdett-Mortensen Model." Manuscript, University of Chicago.

- 2005. "Reassessing the Ins and Outs of Unemployment." Manuscript, University of Chicago.

$\rightarrow$ Solon, G., R. Barsky, and J. Parker. 1994. "Measuring the Cyclicality of Real Wages: How Important Is Composition Bias?" Quarterly Journal of Economics 109, no. 1:1-25.

$\rightarrow$ Stevens, M. 2004. "Wage-Tenure Contracts in a Frictional Labour Market: Firms' Strategies for Recruitment and Retention." Review of Economic Studies 71:535-51. 
